Florida International University FIU Digital Commons

6-19-2018

\title{
Short Selling: Implications for Corporate Governance and Capital Structure
}

Mohammad Anisur Rahman

mrahman@fiu.edu

DOI: $10.25148 /$ etd.FIDC006905

Follow this and additional works at: https://digitalcommons.fiu.edu/etd

Part of the Corporate Finance Commons, and the Finance and Financial Management Commons

\section{Recommended Citation}

Rahman, Mohammad Anisur, "Short Selling: Implications for Corporate Governance and Capital Structure" (2018). FIU Electronic Theses and Dissertations. 3731.

https://digitalcommons.fiu.edu/etd/3731

This work is brought to you for free and open access by the University Graduate School at FIU Digital Commons. It has been accepted for inclusion in FIU Electronic Theses and Dissertations by an authorized administrator of FIU Digital Commons. For more information, please contact dcc@fiu.edu. 


\section{FLORIDA INTERNATIONAL UNIVERSITY}

Miami, Florida

SHORT SELLING: IMPLICATIONS FOR CORPORATE GOVERNANCE AND CAPITAL STRUCTURE

A dissertation submitted in partial fulfillment

of the requirements for the degree of

DOCTOR OF PHILOSOPHY

in

BUSINESS ADMINISTRATION

by

Mohammad Anisur Rahman

2018 
To: Dean Joanne Li

College of Business

This dissertation, written by Mohammad Anisur Rahman, and entitled Short Selling: Implications for Corporate Governance and Capital Structure, having been approved in respect to style and intellectual content, is referred to you for judgment.

We have read this dissertation and recommend that it be approved.

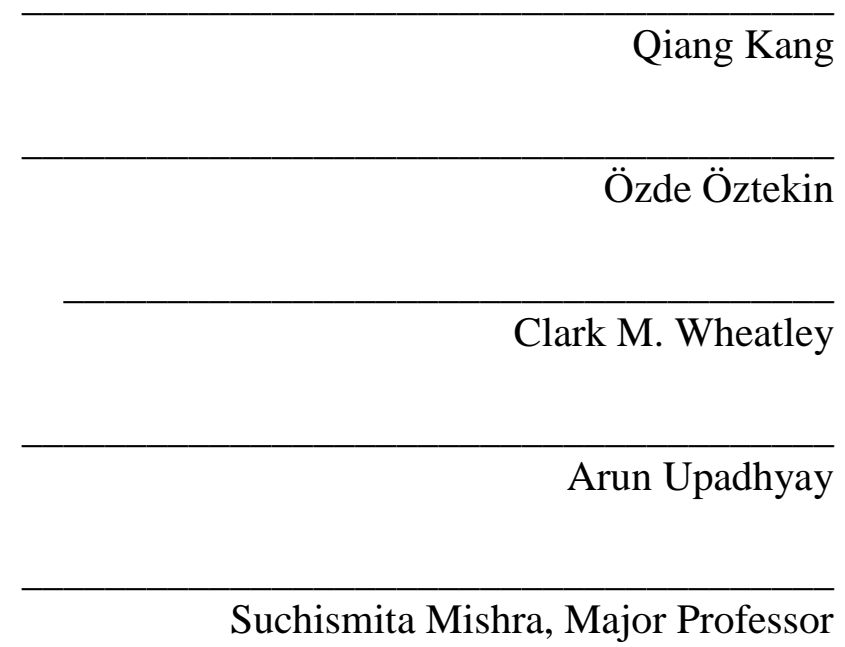

Date of Defense: June 19, 2018

The dissertation of Mohammad Anisur Rahman is approved.

Dean Joanne Li
College of Business

College of Business

Andrés G. Gil

Vice President for Research and Economic Development and Dean of the University Graduate School

Florida International University, 2018 
(C) Copyright 2018 by Mohammad Anisur Rahman

All rights reserved. 


\section{DEDICATION}

I dedicate this dissertation to all members of my family, especially to my great parents, who never stop giving of themselves. 


\section{ACKNOWLEDGMENTS}

I would like to thank Dr. Suchismita Mishra, Dr. Özde Öztekin, Dr. Arun Upadhyay, Dr. Qiang Kang, and Dr. Clark M. Wheatley, members of the dissertation committee for their helpful suggestions and continued support. I would like to express my special gratitude to my advisor Dr. Suchismita Mishra for her kind guidance, valuable feedback, and inspiration over the years. I sincerely appreciate the valuable time and expertise she has contributed. She has been extremely patient with me and supportive in numerous ways, from writing magnificent recommendation letters to never missing an opportunity to put in a good word for me to her colleagues or acquaintances about my research potentials. I also have special appreciation for Dr. Özde Öztekin without whom this dissertation would not be as promising as it is today. She has helped me tremendously to clarify my thoughts and address my research questions in an organized manner. She has taught me how high-quality research is conducted; I have learned not only from her specific written feedback but also immensely from my discussions with her on the research questions, methodology, and so on.

I owe a great debt of gratitude to my great friend Bakhtear Talukdar for his help and support both academically and emotionally on this challenging road of completing my dissertation. I am also grateful to Dr. Ali M. Parhizgari and Dr. Edward R. Lawrence for their continuous encouragement and positive words throughout the process. I would like to thank Lili Sasso, Jessica K. Ugaz, and Yasemin Shirazi for their kind administrative support. Last but not least, my deep gratitude to my great parents and my wonderful siblings for their unconditional and constant support. 


\section{ABSTRACT OF THE DISSERTATION \\ SHORT SELLING: IMPLICATIONS FOR CORPORATE GOVERNANCE AND \\ CAPITAL STRUCTURE}

by

Mohammad Anisur Rahman

Florida International University, 2018

Miami, Florida

Professor Suchismita Mishra, Major Professor

The literature on short selling documents substantial evidence that short sellers are generally informed investors (e.g., Diamond and Verrecchia, 1987; Asquith and Muelbrook, 1996). This dissertation investigates three specific implications of informed short selling for a firm and its investors.

The first essay investigates if short selling discourages managers from pursuing over-optimistic projects by reducing equity market timing. By conditioning short selling on firm overvaluation, this essay shows that short selling reduces managerial equity market timing and increases leverage. This moderating impact of short selling is more pronounced in smaller firms and those with low institutional ownership or higher intangible assets. Furthermore, the results show that board independence facilitates the above effect of short selling which helps protect shareholder interests.

The second essay investigates if board independence reduces informed short selling prior to earnings announcements. This essay estimates short sellers' correct prediction of the direction of unexpected quarterly earnings through Logistic regression and finds that 
short sellers' correct prediction decreases in firms with independent boards relative to firms with non-independent boards. Furthermore, this effect is more pronounced in firms with CEO duality and large board size. The quasi-natural experiment using the exogenous shock to board independence from the Sarbanes-Oxley Act of 2002, provides further support to our hypotheses.

The third essay provides Sell recommendations by examining pre-announcement short selling of firms ahead of their earnings announcements. The methodology makes Sell recommendations for firms with the highest short position prior to their quarterly earnings announcement. The post-announcement raw, excess, and abnormal returns of firms having the Sell recommendations are statistically and economically significant for multipleholding periods showing the methodology's significant trading strategy implication.

This dissertation significantly contributes to short selling, governance, capital structure, and investment literature. 


\section{TABLE OF CONTENTS}

CHAPTER

PAGE

1. SHORT SELLERS AND MANAGERIAL EQUITY MARKET TIMING ....................1

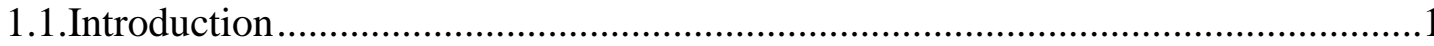

1.2.Literature Review and Development of Hypotheses..............................................6

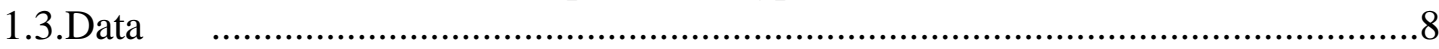

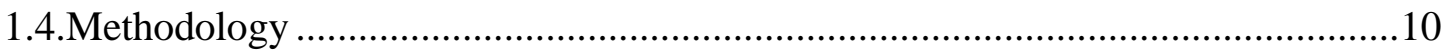

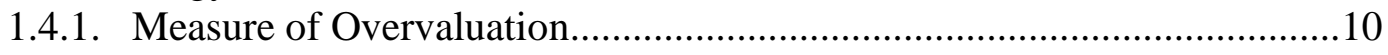

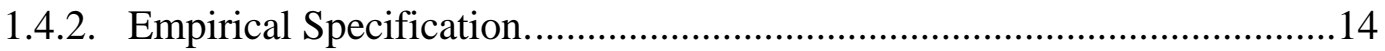

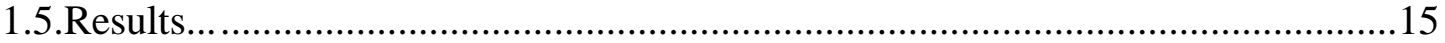

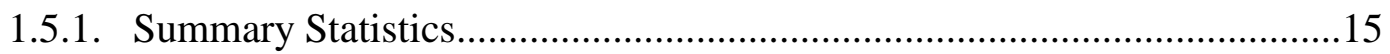

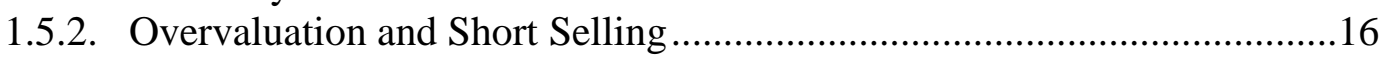

1.5.3. Overvaluation, Short Selling, and Board Independence ............................17

1.5.4. Characteristics of Overvalued Firms and the Intensity of Short Selling

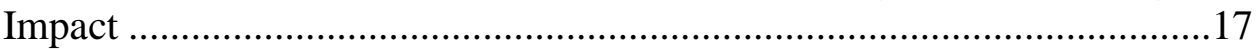

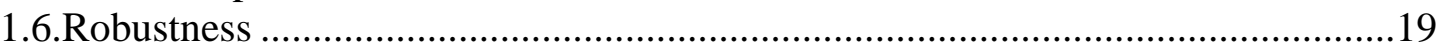

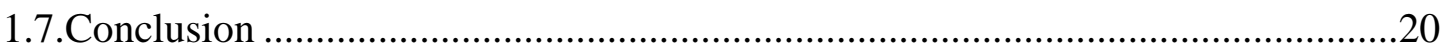

2. DOES BOARD INDEPENDENCE REDUCE INFORMED SHORT SELLING

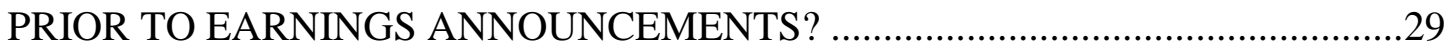

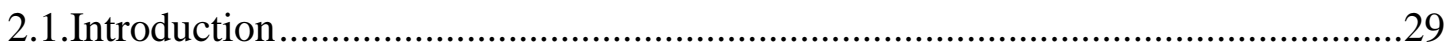

2.2.Literature Review and Development of Hypotheses................................................34

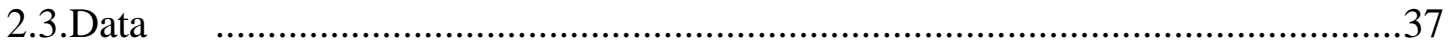

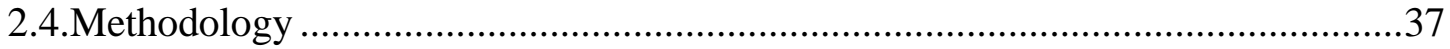

2.4.1. Measure of Unexpected Quarterly Earnings (UQE) ...................................37

2.4.2. Measure of Abnormal Short Interest (ABSI).............................................38

2.4.3. Measure of Informed Short Selling...........................................................38

2.4.4. Model Specification and Estimation Procedure.........................................39

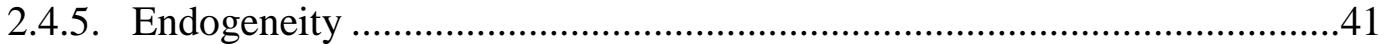

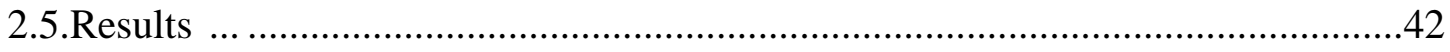

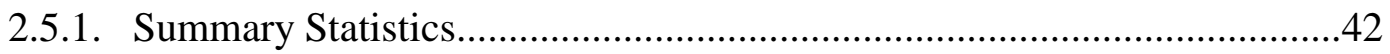

2.5.2. Informed Short Selling and Board Independence .....................................43

2.5.3. Informed Short Selling, Board Independence, and CEO Duality ...............44

2.5.4. Informed Short Selling, Board Independence, and Board Size ..................45

2.5.5. Sarbanes-Oxley Act of 2002, Board Independence, and Informed Short

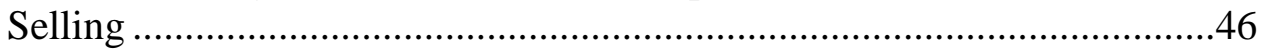

2.6.Conclusion

3. SHORT POSITIONS AND INVESTMENT RECOMMENDATIONS …………......59

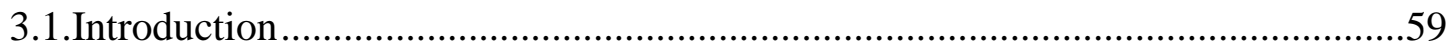

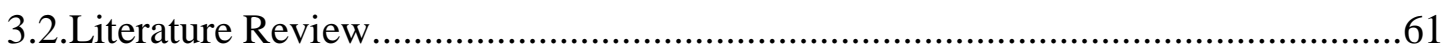

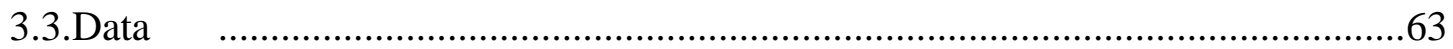

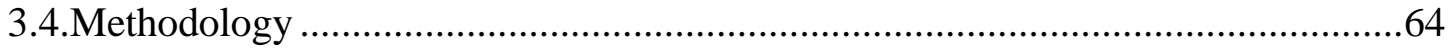




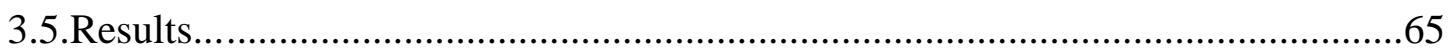

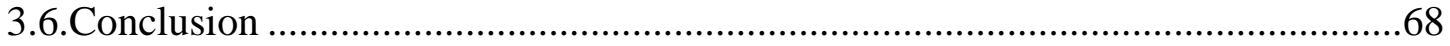

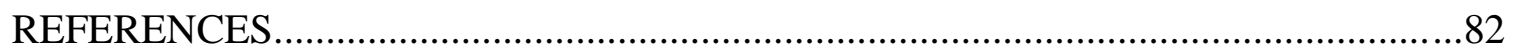

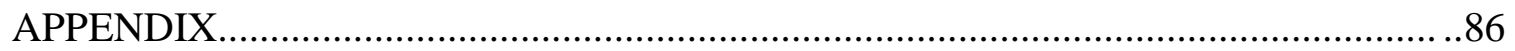

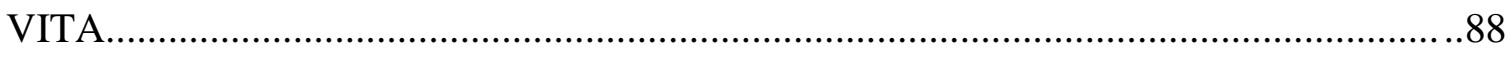




\section{LIST OF TABLES}

TABLE

PAGE

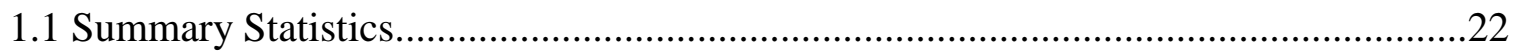

1.2 Impact of Short Selling on Book Leverage ........................................................23

1.3 Impact of Short Selling on Book Leverage and Board Independence ........................24

1.4 Impact of Short Selling on Book Leverage and Firm Size ..................................25

1.5 Impact of Short Selling on Book Leverage and Institutional Ownership ..................26

1.6 Impact of Short Selling on Book Leverage and R\&D.........................................27

1.7 Impact of Short Selling on Book Leverage (Total Liabilities) ...............................28

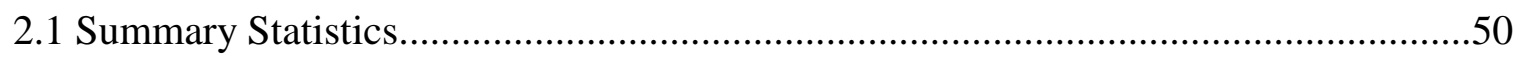

2.2 Informed Short Selling and Board Independence ............................................51

2.3 Informed Short Selling, Board Independence, and CEO Duality .............................53

2.4 Informed Short Selling, Board Independence, and Board Size ..............................55

2.5 Sarbanes-Oxley Act of 2002, Board Independence, and Informed Short Selling .......57

3.1 Monthly Distribution of Quarterly Earnings Announcement ................................. 71

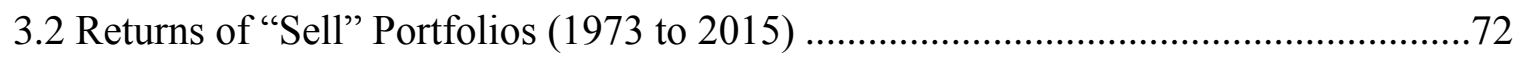

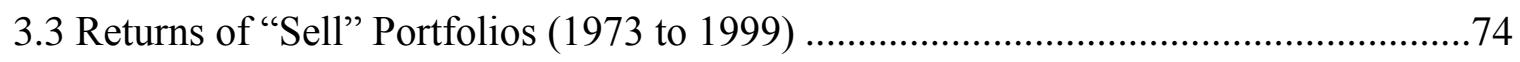

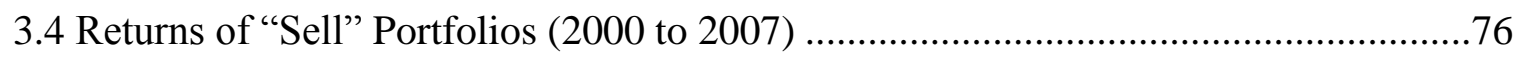

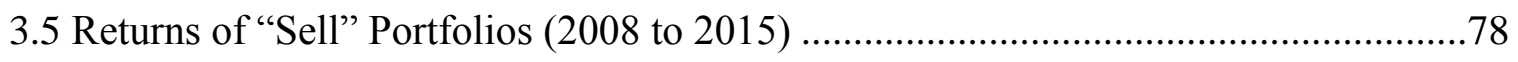

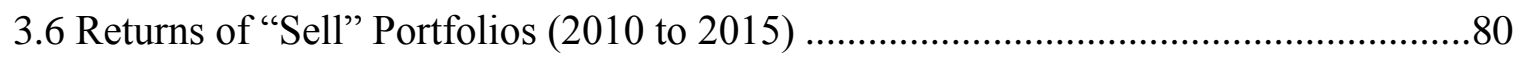




\section{LIST OF FIGURES}

FIGURE

PAGE

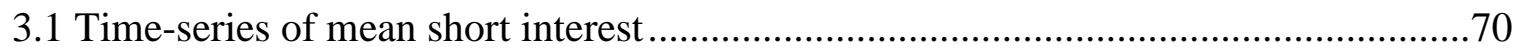




\section{CHAPTER 1: SHORT SELLERS AND MANAGERIAL EQUITY MARKET TIMING}

\subsection{Introduction}

Existing capital structure studies have documented ample evidence of the importance of managerial equity market timing (e.g., Marsh, 1982; Pagano, Panetta, and Zingales, 1998; Ikenberry, Lakonishok, and Vermaelen, 1995; Baker and Wurgler, 2002) in the management of a firm's capital structure. The core idea of these studies is that managers take advantage of the temporary market and/or firm overvaluation to issue shares at higher prices and repurchase shares at lower prices, which eventually affects a firm's capital structure. If firms have a need for external financing to support positive NPV projects, then managerial equity market timing may be considered as a rational choice as issuing equity is the most cost-effective external financing strategy during overvaluation. However, if a firm is overvalued without enough growth projects, which may happen, for example, if the market is over-optimistic about the firm because of information asymmetry, then this overvaluation can exert pressure on managers to pursue overoptimistic projects (Polk and Sapienza, 2009) to support the current price level, and consequently, time the equity market. In this case, overvaluation-driven equity market timing may destroy firm value.

Current studies of equity market timing did not draw a distinction between equity market timing to support future positive $N P V$ projects and equity market timing to take advantage of market sentiment, which may or may not be justified by growth opportunities. In this paper, we aim at addressing this gap by examining the implications of overvaluation on other market participants (i.e., short sellers) and how this may interact with managerial equity market timing. The literature on short selling documents substantial evidence that 
short sellers are able to identify overvalued firms (e.g., Seneca, 1967; Figlewski, 1981; Senchack and Starks, 1993; Asquith and Muelbrook, 1996; Desai et al., 2002). Thus, the same temporary episodes of overvaluation that create opportunities for cheap equity issuance for managers also offer great opportunities for short selling in anticipation of future price decline. With further evidence of short sellers adding to price discovery in the financial markets (e.g., Bris, Goetzmann, and Zhu, 2007; Boehmer, Jones, and Zhang, 2008; Boehmer and Wu, 2013; Saffi and Sigurdsson, 2011), managers may want to consider the adverse information embedded in short selling when deciding whether to cater to high market sentiment and issue equity by taking advantage of the overvaluation. Thus, short sellers may provide important check and balances in managerial equity market timing by uncovering important adverse information about future projects, which is the focus of this paper.

Drawing on the above existing empirical evidence that managers may invest in over-optimistic projects under overvaluation and that short selling is high if a firm is overvalued, we hypothesize that conditioned on overvaluation, short selling will uncover adverse information about the firm (e.g. overinvestment in projects), decrease equity issuance, and thus will result in an increase in leverage. We test this hypothesis on both book and market leverage and document similar results.

The first challenge in testing our hypothesis is to come up with a reliable measure of misvaluation to evaluate firm leverage behavior under overvaluation. Existing literature frequently uses market-to-book $(M B)$ (see, e.g., Baker and Wurgler, 2002; Kayhan and Titman, 2007) as a measure of misvaluation. However, $M B$ includes book value, a backward-looking measure of the fundamental value of a firm, and therefore, a high $M B$ 
may reflect market expectations of high growth opportunities or overvaluation or both (see, e.g., Hovakimian, 2006; Dong, Hirshleifer, and Teoh, 2012). Therefore, it is difficult to test the effects of overvaluation on capital structure based solely on $M B$ (Dong, Hirshleifer, and Teoh, 2012). In this paper, we address this issue by adopting an alternative measure of misvaluation, value-to-price $(V P)$, where value is a forward-looking measure of the fundamental value $(V)$ of a firm based on the residual income model of Ohlson (1995). ${ }^{1}$ By including a forward-looking measure instead of the historical book value of equity, $V P$ purges growth expectations from market prices reasonably well and provides us with a more refined measure of misvaluation than $M B$. We then use $V P$ to estimate an increase in overvaluation and condition an increase in $S I$ on an increase in overvaluation to examine the impact of short selling on leverage during overvaluation. Following the convention in the short selling literature (Dechow et al., 2001; Asquith, Pathak, and Ritter, 2005; Karpoff and Lou, 2010; Henry, Kisgen, and Wu, 2011; Grullon, Michenaud and Weston, 2015), we divide a firm's monthly/bi-monthly short interest $(S I)$ by its total shares outstanding to proxy for short selling. We use Ordinary Least Square (OLS) to regress leverage on the above conditioning variable (an increase in SI conditioned on an increase in overvaluation), $\mathrm{MB}$, and the traditional determinants of leverage as identified in past studies (Titman and Wessels, 1988; Rajan and Zingales, 1995; Hovakimian, Opler, and Titman, 2001; Welch, 2004; Baker and Wurgler, 2002; Kayhan and Titman, 2007). ${ }^{2}$ The results from estimating

\footnotetext{
${ }^{1}$ Prior literature has implemented the residual income model of Ohlson (1995) to estimate $V P$ to use as a measure of misvaluation in both repurchase (D'Mello and Shroff, 2000) and equity issuance (Dong, Hirshleifer, and Teoh, 2012) decisions.

${ }^{2}$ We include $M B$ along with $V P$ because the forward-looking fundamental value $V$ may not perfectly capture growth opportunities and $M B$ is more heavily weighted toward information about growth opportunities than $V P$. Thus, including both in the model makes the model stringent (see, e.g., Dong, Hirshleifer, and Teoh, 2012).
} 
the above model show that book leverage increases by $1.4 \%$ when short selling increases after an increase in overvaluation.

The governance literature provides an excellent opportunity to test our hypothesis that short selling disciplines the managers, attenuates managerial equity market timing, and thereby increases leverage. Specifically, this literature finds that independent directors are better at monitoring management (see, e.g., Nguyen and Nielsen, 2010). Accordingly, we hypothesize that the impact of short selling will be higher if the firm's board is independent, as independent directors will be more willing to pay attention to short sellers' opinions than dependent directors due to agency problems. To test this hypothesis, we estimate our model separately on the subsamples of firms with independent boards and non-independent boards. Following Shivdasani and Yermack (1999), we classify a board as independent if independent directors constitute the majority of the board. The results show that the moderating impact of short selling on book leverage is significantly positive among firms with independent boards and insignificant among firms with non-independent boards. This finding supports the above hypothesis.

Existing studies document that some firm characteristics increase the likelihood of a firm to be overvalued. Dong, Hirshleifer, and Teoh (2012) note that smaller firms are harder to value and are subject to an increased likelihood of misvaluation. Many studies on short selling (Miller, 1977; Harrison and Kreps, 1978; Allen, Morris, and Postlewaite, 1993; Chen, Hong, and Stein, 2002; Scheinkman and Xiong, 2003; Hong and Stein, 2003) argue and provide empirical support for the idea that stock prices suffer from an upward bias in the presence of short selling constraints. Furthermore, high research and development $(R \& D)$ expenses may indicate good growth prospects. However, because 
market participants will have differences in opinions, they will also attach different values to the prospects of the $\mathrm{R} \& \mathrm{D}$, leading to an increased likelihood of misvaluation. Given the above evidence of how firm size, short selling constraints, and $R \& D$ may affect the likelihood of misvaluation, we hypothesize that the impact of short selling on leverage will be more prominent in smaller firms, in firms with lower institutional ownership (low institutional ownership proxying for high short selling constraints), or in firms with higher $R \& D$. We estimate our model on Low, Medium, and High measures of Size (firm size), $R \& D$, and institutional ownership and find results supporting our above hypothesis. Overall, our results suggest that short selling has an offsetting impact on equity market timing for overvalued firms, leading to an increase in leverage, and especially so for firms with independent boards, smaller firms, firms with lower institutional ownership, and firms with more intangible assets.

Our study makes valuable contributions to multiple strands of literature. Based on our literature reviews, this study is the first of its kind to examine equity market timing in relation to short selling. Past studies focused only on the managerial incentives to time equity market when the firm is overvalued. Our study links the implications of overvaluation for other market participants to managerial incentives and shows that equity market timing is sensitive to short selling. Thus, our results contribute to a better understanding of managerial decision making with respect to external financing. By showing that short sellers provide important check and balances in the financial markets for proper asset allocation, we add to the short selling literature, particularly to the marketbased monitoring mechanism of short selling. We also add to the governance literature as 
our results show that board independence strengthens the disciplining impact of short selling on managerial market timing.

\subsection{Literature Review and Development of Hypotheses}

If a firm is overvalued, that is, if the firm does not have enough growth projects to justify its valuation, then short sellers, who are considered informed investors, will short sell that stock in anticipation of a future decline in price. The adverse information embedded in high short selling will discourage managers to pursue overoptimistic projects and reduce their issuance of equity which will result in an increase of leverage. This leads to our first hypothesis:

Hypothesis 1. The leverage of an overvalued firm will increase in response to an increase in short selling, as short selling attenuates managerial equity market timing.

The above hypothesis suggests that managers will pay attention to the short sellers' opinions as embedded into the short position and adjust their equity market timing accordingly. Governance literature shows that independent directors are better at monitoring management (Nguyen and Nielsen, 2010). Therefore, board independence should facilitate the incorporation of short sellers' adverse information into managerial decision making, which leads to our second hypothesis:

Hypothesis 2. The moderating impact of short selling on managerial equity market timing during overvaluation will be more pronounced in firms with independent boards than in firms with non-independent boards, as independent directors will be more willing to pay attention to short sellers' opinions than non-independent directors due to lower agency problems, leading to a higher increase in leverage. 
Existing studies document that some firm characteristics (e.g., small firm size, high $R \& D$, low institutional ownership) increase the likelihood of a firm to be overvalued. Therefore, we also expect that short sellers will actively target the firms with such characteristics and the impact of short selling on leverage will be more prominent among such firms. Below we discuss this issue thoroughly and form our hypotheses accordingly.

Dong, Hirshleifer, and Teoh (2012) find that equity issuance increases with firm overvaluation. Furthermore, these researchers find that this effect on equity issuance is more pronounced in smaller firms because smaller firms are harder to value and are subject to an increased likelihood of misvaluation. Many influential studies have examined the implications of short selling constraints (Miller, 1977; Harrison and Kreps, 1978; Allen, Morris, and Postlewaite, 1993; Chen, Hong, and Stein, 2002; Scheinkman and Xiong, 2003; Hong and Stein, 2003). These studies theorize and provide empirical support to the idea that when there are no short selling constraints, pessimistic investors can easily short sell securities, counterbalancing optimistic valuation. As a result, stock prices, on average, do not suffer significant upward bias. However, when short selling constraints exist, pessimistic investors find it difficult to short sell securities, which cause a positive bias in stock prices. Some of these studies use institutional ownership to proxy for short selling constraints and find that when institutional ownership increases (decreases), short selling constraints decrease (increase) (Nagel, 2004; Chen, Hong, and Stein, 2002). The presence of intangible assets in a firm makes it difficult for the market to value it correctly. For example, high research and development expenses $(R \& D)$ may indicate good growth prospects. However, because market participants will have differences in opinions, they will also attach different values to the prospects of $R \& D$, leading to an increased likelihood 
of overvaluation or undervaluation. In studying the effects of overvalued equity on financing decisions, Dong, Hirshleifer, and Teoh (2012) document that the effect of misvaluation on issuances is stronger among firms with higher proportions of intangible assets. Using discretionary accruals as a proxy for misvaluation, Polk and Sapienza (2009) find that investment is more sensitive to misvaluation among firms with higher $R \& D$ intensity. The above discussion leads to the following hypotheses:

Hypothesis 3. The moderating impact of short selling on managerial equity market timing during overvaluation will be more pronounced in smaller firms, in firms with lower institutional ownership (lower institutional ownership proxying for higher short selling constraints), or in firms with higher $R \& D$.

\subsection{Data}

For our analysis, we use annual fundamental and monthly/bi-monthly short interest data from Supplemental Short Interest File of Compustat. ${ }^{3}$ We obtain market data from the Center for Research in Security Prices (CRSP). Short interest data are available only from 1973 restricting our initial sample period from 1973 to 2014. We limit our analysis to the U.S common stocks (CRSP share codes 10 and 11). We exclude financial services firms (SIC codes 6000-6999) and regulated utility firms (SIC codes 4900-4999) from our sample. Furthermore, following Kayhan and Titman (2007) and Liu (2009), we exclude firms with book values of assets smaller than $\$ 10$ million or book debt-to-book assets ratio larger than one. The presence of missing values and use of lagged explanatory variables

\footnotetext{
${ }^{3}$ Beginning in September 2007, member firms of Amex, NASD and NYSE are required to submit short interest information twice a month. See Securities Exchange Act Release No. 55406 (March 6, 2007), 72 FR 11071 (March 12, 2007) (order approving SR-NASD-2006-131, SR-NYSE-2006-111, SR-Amex-2007-005).
} 
further reduce our sample size, resulting in 50,315 firm-year observations spanning the period from 1974 to 2014. For our value-to-price $(V P)$, we use I/B/E/S mean forecasted earnings per share (EPS) data, which are available only since January 1979, and thus further reduces our final sample size to only 26,270 (book leverage sample) and 26,263 (market leverage sample) firm-year observations.

Following the short selling literature (Dechow et al., 2001; Asquith, Pathak, and Ritter, 2005; Boehme, Danielsen, and Sorescu, 2006; Karpoff and Lou, 2010; Henry, Kisgen, and $\mathrm{Wu}, 2011$; Grullon, Michenaud and Weston, 2015), we divide a firm's monthly/bi-monthly short interest $(S I)$ by its total shares outstanding to proxy for short selling $(S I)$. To capture a greater level of variation and allow more informativeness in short selling, we take the average of $S I$ from four months after the fiscal year-end to three months prior to the beginning of the next fiscal year and deflate it with the cross-sectional mean of SI. We maintain a gap of four months to match fundamental data as of the fiscal year-end to avoid look-ahead bias because it takes approximately four months for the $10-\mathrm{K}$ of most firms to be publicly available (see, e.g., Alford, Jones, and Zmijewski, 1994). We also maintain a gap of three months prior to next fiscal year-end because a firm is unlikely to change its capital structure immediately.

We perform our analysis on both book leverage and market leverage because existing literature adopts book leverage (e.g., Shyam-Sunder and Myers, 1999), market leverage (e.g., Welch, 2004), and both book and market leverage (e.g., Baker and Wurgler, 2002; Kayhan and Titman, 2007). We define book leverage as book debt to total assets (Compustat item [6]), where book debt is the sum of long-term debt (Compustat item [9]) and debt in current liabilities (Compustat item [34]). We define market leverage as book 
debt divided by the result of total assets minus book equity plus market equity, where market equity is defined as common shares outstanding (Compustat item [25]) times price (Compustat item [199] $)^{4}$.

We construct several control variables that past capital structure studies have documented as reliable determinants of firm leverage (Titman and Wessels, 1988; Rajan and Zingales, 1995; Hovakimian, Opler, and Titman, 2001; Welch, 2004; Baker and Wurgler, 2002; Kayhan and Titman, 2007). These determinants include market-to-book ratio $(M B)$ defined as total assets (Compustat item [34]) less book equity (Compustat item [144]) plus market equity (defined above), all divided by total assets; property, plant, and equipment (PPE) defined as net property, plant, and equipment (Compustat item [141]) scaled by total assets; profitability $(E B I T D)$ defined as operating income before depreciation (Compustat item [13]) scaled by total assets; research and development expenses $(R \& D)$ defined as research and development expenses (Compustat item [46]) scaled by net sales (Compustat item [117]); R\&DDummy, a dummy variable that is set to one if the firm has no $R \& D$ expenses, otherwise zero; selling expenses ( $S E$ ) defined as selling expenses (Compustat item [132]) scaled by net sales, and firm size (Size) defined as the logarithmic value of net sales.

\subsection{Methodology}

\subsubsection{Measure of Overvaluation}

In this paper, our objective is to examine how short selling affects leverage when a firm is overvalued. Therefore, an important task for our empirical analysis is to construct a reliable

\footnotetext{
${ }^{4}$ We perform our analysis on several alternative definitions of leverage and note similar results. We discuss this analysis in our robustness section.
} 
measure of misvaluation which can then be analyzed for overvaluation or undervaluation. Existing literature frequently uses market-to-book $(M B)$ to measure misvaluation (see, e.g., Baker and Wurgler, 2002; Kayhan and Titman, 2007). However, there are non-trivial issues in using $M B$ as a measure of misvaluation. $M B$ includes a backward-looking measure of the fundamental value of a firm, book value, whereas current market price may reflect both misvaluation and growth opportunities. Therefore, a high $M B$ may reflect market expectations of high growth opportunities or overvaluation or both (see, e.g., Hovakimian, 2006; Dong, Hirshleifer, and Teoh, 2012), isolation of which is difficult. Therefore, it is difficult to test the effects of overvaluation on capital structure based solely on $M B$ (Dong, Hirshleifer, and Teoh, 2012). However, an estimate of the "true" fundamental value of a firm, which incorporates growth opportunities reasonably well, scaled by current market price would yield a more refined (less confounded with growth opportunities) measure of misvaluation. The residual income model of Ohlson (1995) provides such an estimate of "true" fundamental value, also called "intrinsic value" $(V)$. Several past studies rely on this methodology to estimate intrinsic value and misvaluation. Lee, Myers, and Swaminathan (1999) use the residual income model of Ohlson (1995) to obtain the intrinsic value of the 30 stocks in the Dow Jones Industrial Average (DJIA). Frankel and Lee (1998) use it to predict cross-sectional stock returns in the U.S. D'Mello and Shroff (2000) use it to estimate misvaluation to examine whether undervaluation affects repurchase decisions. Dong, Hirshleifer, and Teoh (2012) use it to examine how equity overvaluation affects corporate financing decisions. As in previous research on intrinsic value and misvaluation, we also implement the residual income model of Ohlson (1995) to construct a more refined measure of misvaluation than $M B$. 
We follow Lee, Myers, and Swaminathan (1999) and Dong, Hirshleifer, and Teoh (2012) in implementing the residual income model of Ohlson (1995). Ohlson (1995) shows that if a firm's earnings and book value follow "clean surplus" accounting, then the intrinsic value of a stock is equal to book value plus the discounted value of an infinite sum of expected residual incomes. ${ }^{5}$ Mathematically, intrinsic value $(V)$ can be expressed in the following manner:

$$
V_{t}=B_{t}+\sum_{i=1}^{\infty} \frac{E_{t}\left[\left\{R O E_{t+i}-r(e)_{t}\right\} B_{t+i-1}\right]}{\left[1+r(e)_{t}\right]^{i}}
$$

where $t$ indexes time, $E$ is the expectations operator, $B$ is the book value of equity, $R O E$ is the return on equity, and $r(e)$ is the firm's annualized cost of equity capital.

The above equation expresses firm value in terms of an infinite series. For practical purposes, we adopt a two-stage approach to estimate the intrinsic value: (1) Forecast earnings explicitly for the next three years and (2) Estimate the terminal value taking the period $t+3$ residual income as a perpetuity ${ }^{6}$. Following this two-stage approach, we express $V$ as below:

$$
\begin{gathered}
V_{t}=B_{t}+\frac{\left[\left\{R O E_{t+1}^{f}-r(e)_{t}\right\} B_{t}\right]}{1+r(e)_{t}}+\frac{\left[\left\{R O E_{t+2}^{f}-r(e)_{t}\right\} B_{t+1}\right]}{\left[1+r(e)_{t}\right]^{2}} \\
+\frac{E_{t}\left[\left\{R O E_{t+3}^{f}-r(e)_{t}\right\} B_{t+2}\right]}{\left[1+r(e)_{t}\right]^{2} r(e)_{t}}
\end{gathered}
$$

\footnotetext{
${ }^{5}$ Clean surplus accounting requires all gains and losses affecting the book value of a stock to be included in earnings. This implies that the periodic change in book value is equal to earnings minus dividends.

${ }^{6}$ Lee, Myers, and Swaminathan (1999) use three different forecast horizons, namely 3, 12, and 18, but document that the choice of forecast horizon does not affect the quality of the estimate of the intrinsic value $(V)$.
} 
where $R O E_{t+1}^{f}$ is the forecasted return on equity for period $t+1$ and the last term discounts the period $t+3$ residual income as a perpetuity. The underlying assumption of the model is that the expected residual earnings remain constant after year $t+3$ so that the discount rate for the perpetuity is the firm's cost of equity capital (see, e.g., Lee, Myers, and Swaminathan, 1999; Dong, Hirshleifer, and Teoh, 2012). Following Dong, Hirshleifer, and Teoh (2012), the forecasted $R O E$ is computed as:

$$
R O E_{t+i}^{f}=\frac{E P S_{t+i}^{f}}{\bar{B}_{t+i-1}}
$$

where $E P S_{t+i}^{f}$ is $\mathrm{I} / \mathrm{B} / \mathrm{E} / \mathrm{S}$ mean forecasted $E P S$ for period $t+i$ and

$$
\bar{B}_{t+i-1}=\frac{B_{t+i-1}+B_{t+i-2}}{2}
$$

This approach requires forecasting the future value of book equity (for period $t+2$ and $t+3)$. We estimate future values of book equity as:

$$
B_{t+i}=B_{t+i-1}+(1-k) E P S_{t+i}^{f}
$$

where $k$ is the dividend payout ratio computed by dividing actual dividends from the last fiscal year by earnings over the same time period. Following Lee, Myers, and Swaminathan (1999) and Dong, Hirshleifer, and Teoh (2012), we implement the following additional procedures. First, earnings are assumed to be on average $6 \%$ of total assets if $k$ is negative due to negative earnings. That is, the amount of dividends paid divided by the results of 0.06 times total assets replaces the original estimate of $k$ when $k$ is negative. Second, observations where $k$ is greater than one or book value of equity is negative are 
simply deleted. Finally, a constant discount rate of $12.5 \%$ is used for the firm's annualized cost of equity capital. ${ }^{7}$

\subsubsection{Empirical Specification}

To examine how short selling affects leverage when the firm is overvalued based on the misvaluation measure of $V P$, we first define two dummy variables: VPDummy and SIDummy. VPDummy is coded one if changes in $V P(\triangle V P)$ are negative, and zero otherwise. Similarly, SIDummy is coded one if changes in $S I(\Delta S I)$ are positive, and zero otherwise. Then, we construct an interaction term between the above two dummy variables and multiply by $\triangle S I(I N T E R A C T)$. Because $\triangle V P=1$ indicates an increase in overvaluation and $\Delta S I=1$ indicates an increase in $S I$, which is expected when short sellers do not agree with the existing valuation, the above interaction term INTERACT captures the impact of short selling on firm leverage during times of firm overvaluation, and by multiplying INTERACT with $\triangle S I$, we also capture how sensitive leverage is with respect to an increase in $\triangle S I$. In our model, we include INTERACT, $\triangle V P, \triangle S I, M B$, and several firm characteristics following past capital structure studies as discussed in the previous section. We include $M B$ in the same model to make our test most stringent, as $M B$ is more heavily weighted toward information about growth opportunities than $V P$, and $V P$ may still contain information about growth opportunities because we use analysts' forecasts only for few years ahead in estimating the intrinsic value (V). Following Kayhan and Titman (2007), we also control for industry fixed effects. Therefore, our model is:

\footnotetext{
${ }^{7}$ Dong, Hirshleifer, and Teoh (2012) also use Capital Asset Pricing Model (CAPM) and Fama-French threefactor model to estimate cost of equity and obtain similar results.
} 


$$
\begin{aligned}
L_{i, t}=\alpha_{0}+ & \beta_{1} \text { INTERACT }_{i, t-1}+\beta_{2} \Delta S I_{i, t-1}+\beta_{3} \text { SIDummy }_{i, t-1} \\
& +\beta_{4} \text { VPDummy }_{i, t-1}+\theta X_{i, t-1}+\delta_{1} \text { Industrydummy }+\varepsilon_{i, t}
\end{aligned}
$$

where $t$ indexes time and $i$ indexes firm; $L$ represents leverage; $\Delta S I$ is changes in short interest; SIDummy is a dummy variable coded one when $\Delta S I$ is positive, else zero; $V P D$ ummy is a dummy variable coded one when $\triangle V P$ is negative, else zero; INTERACT is an interaction term among $\triangle V P$ Dummy, SIDummy, and $\Delta S I ; X$ is a vector of firm characteristics that affects leverage, including market-to-book (MB), Prop., Plant \& Equip. $(P P E)$, Profitability (EBITD), Selling Expense (SE), Reseach \& Development Expenses ( $R \& D), R \& D D u m m y$, and firm size (Size). We implement the above model separately for book and market leverage because current literature adopts both. As per our hypothesis, we expect INTERACT to be positively correlated with leverage (both book and market leverage).

\subsection{Results}

\subsubsection{Summary Statistics}

Panel A of Table 1.1 shows the descriptive statistics of our dependent and independent variables. We calculate the statistics after winsorizing the variables at the 1st and 99th percentiles within each fiscal year to mitigate the impact of outliers. The statistics of the variables in our study are very close to the statistics reported in the comparable studies. For example, the mean values of $B L$ and Size are 0.21 and 6.78, respectively, which compare closely to 0.24 and 5.23, the mean values of leverage and Size, respectively, in Hovakimian (2006). Similarly, the mean values of $P P E, M B$, and EBITD are 0.30, 1.74, and 0.14 , respectively, which compare closely to $0.32,1.73$, and 0.10 , the mean values of 
$P P E, M B$, and EBITD, respectively, in Liu (2009). The mean value of SI is 0.035 which compares well to the mean value of 0.022 for SI in Hirshleifer, Teoh, and Yu (2011). Panel B shows the Pearson's Correlation Coefficients among the variables in our study which show that all of the variables are strongly significant in directions consistent with prior studies. For example, in consistence with prior studies (Baker and Wurgler, 2002; Kayhan and Titman, 2007), $M B, E B I T D, S E$, and $R \& D$ are all negatively, and $P P E$ and Size are positively, correlated with $B L$ and $M L$. Furthermore, we note that both $S I$ and $\Delta S I$ are positively correlated with $B L$ and $M L$.

\subsubsection{Overvaluation and Short Selling}

Our first hypothesis states that the leverage of a firm will increase with an increase in short selling conditional on an increase in overvaluation. To test this hypothesis, we estimate Eq. (6) where our variable of interest is INTERACT. As per our hypothesis, we expect INTERACT to be positively significant. We present the results in Table 1.2 which show that INTERACT is positive and strongly significant. The coefficient estimate of INTERACT is 0.014 indicating that $B L$ increases by $1.4 \%$ following an increase in $S I$ conditioned on an increase in firm overvaluation. The strongly significant negative coefficient of VPDummy also captures the well-documented evidence of managerial equity market timing when a firm is overvalued. Furthermore, the significantly positive coefficient estimate of SIDummy indicates that regardless of the direction of the change in the past firm valuation (increase or decrease), $B L$ increases as $S I$ increases. By comparing the magnitude of the coefficients of SIDummy and INTERACT, it is clear that $B L$ is over two times more sensitive (we compute this by dividing the coefficient estimate of 
INTERACT by the coefficient estimate of SIDummy) to an increase in SI if the increase happens subsequent to an increase in firm overvaluation.

\subsubsection{Overvaluation, Short Selling, and Board Independence}

Our hypothesis 2 states that the impact of short selling will be more pronounced in firms with independent boards compared to firms with non-independent boards. To test this hypothesis, we divide our sample into two subsamples - (1) Firms with nonindependent boards and (2) Firms with independent boards. Following Shivdasani and Yermack (1999), we classify a board as independent if independent directors constitute a majority of the board. Then, we estimate Eq. (6) separately in these two subsamples. Table 1.3 includes the results which show that INTERACT is significantly positive in firms with independent boards and insignificant in firms with non-independent boards. Furthermore, the coefficient estimate of INTERACT in firms with independent boards is higher than in the entire sample of firms in Table 1.2 (0.016 vs. 0.014).The insignificant coefficient estimate of INTERACT in firms with non-independent boards may indicate that the agency costs in poor governance firms (proxied by non-independent boards) may be so high that shareholders of these firms do not enjoy the benefits of external market feedback in the form of important adverse information embedded in high short position. These results support the argument in our second hypothesis.

1.5.4 Characteristics of Overvalued Firms and the Intensity of Short Selling Impact

Hypothesis 3 states that the impact of short selling will be more pronounced in smaller firms, in firms with low institutional ownership, or in firms with higher R\&D. To test this hypothesis with respect to firm size, we divide our sample into three equal groups, Low, Medium, and High, based on their Size. Following Arnold et al. (2005), we define 
Size as the logarithmic value of the market value of equity. ${ }^{8}$ We estimate Eq. (6) in each of these subsamples of firms separately and report the results in Table 1.4. The results show that the coefficient estimate of INTERACT is positive and strongly significant in each Size group; however, the coefficient estimate of INTERACT is the highest in the Low Size group. The coefficient estimates of INTERACT are 0.019, 0.009, and 0.01 in Low, Medium, and High Size groups, respectively. The coefficient estimate of INTERACT in the smallest firms (Low Size group) is almost twice the estimate in the largest (High Size group) firms. Therefore, these results suggest that the impact of short selling on $B L$ is stronger in the group of smaller firms which is also consistent with the argument in the past studies that smaller firms are subject to an increased likelihood of misvaluation.

To test hypothesis 3 with respect to institutional ownership, we divide the entire sample into Low, Medium, and High institutional ownership firms based on the percent of institutional ownership. Following existing studies (see, e.g., Nagel, 2004; Dechow et al., 2001), we define institutional ownership as the total number of shares held by institutions divided by the number of shares outstanding measured at the fiscal year-end. We estimate Eq. (6) in each of these subsamples of firms separately and report the results in Table 1.5. The results show that the coefficient estimate of INTERACT is positive and strongly significant in Low and Medium institutional ownership groups and insignificant in High institutional ownership group, providing good evidence in support of our hypothesis. The coefficient estimates of INTERACT are 0.022, 0.024, and 0.005 in Low, Medium, and High institutional ownership groups, respectively.

\footnotetext{
${ }^{8}$ We obtain similar results by using other measures of Size including the logarithmic value of fiscal year-end total assets following Anderson, Reeb, and Zhao (2012).
} 
We follow the same process for $R \& D$ expenses $(R \& D)$. Specifically, we construct Low, Medium, and High $R \& D$ samples of firms based on $R \& D$, where $R \& D$ is defined as total research and development expenses divided by net sales. However, given the earlier findings that the impact of short selling is more pronounced among smaller firms, we create Low, Medium, and High $R \& D$ samples from only the High Size firms to avoid the effect of $R \& D$ to be confounded with the Size effect. We estimate Eq. (6) in each of these subsamples of firms separately and present the results in Table 1.6. The results show that the coefficient estimate of INTERACT is significantly positive only in High $R \& D$ firms. Specifically, the coefficient estimate of INTERACT is 0.017 in High $R \& D$ firms which is larger than the estimate from the entire sample in Table $1.2(0.014)$, indicating that the short selling impact is driven by firms with high $R \& D$.

\subsection{Robustness}

Existing studies vary in their approaches to define leverage. For example, previous studies differ in how they define debt. In our paper, we have defined debt as the sum of long-term debt and debt in current liabilities. We do not use total liabilities as items like accounts payable are used for transaction purposes rather than for financing (see, e.g., Hovakimian 2006; Korajczyk and Levy, 2003; Leary and Roberts, 2005). However, other studies use total liabilities (see, e.g., Baker and Wurgler, 2002) as debt in their definitions of leverage. Therefore, in this section, to check the robustness of our results to alternative definitions of leverage, we use total liabilities as debt in both book and market leverage and estimate Eq. (6). Table 1.7 includes the results of book leverage which show that INTERACT is positive and strongly significant. Furthermore, the estimates are very close to what we obtained previously in Table 1.2 (0.013 vs. 0.014$)$. 


\subsection{Conclusion}

Overvalued equity provides an opportunity to raise capital in a cost-effective manner. Past studies find evidence that managers tend to issue shares at high prices and repurchase shares at low prices (e.g., Marsh, 1982; Pagano, Panetta, and Zingales, 1998; Ikenberry, Lakonishok, and Vermaelen, 1995; Baker and Wurgler, 2002). However, if an overvalued firm issues equity by timing the equity market, then this firm may lose value as the new capital will go into sub-optimal projects or stay as excess cash. Drawing on the evidence of short selling literature that short sellers are able to identify overvalued firms (e.g., Seneca, 1967; Figlewski, 1981; Senchack and Starks, 1993; Asquith and Muelbrook, 1996; Desai et al., 2002), we hypothesize that short selling, by revealing adverse information about future projects, will discourage managers from pursuing over-optimistic projects which will reduce equity market timing and increase leverage. We test this hypothesis with a measure of misvaluation based on value-to-price $(V P)$, where value is a forward-looking measure of firm fundamental value and therefore, control for the growth effects reasonably well and isolate the effects of overvaluation. The results show that leverage increases in response to an increase in short selling conditional on an increase in overvaluation, as our hypothesis suggests. This moderating effect of short selling is significantly positive among firms with independent boards and insignificant among firms with non-independent boards, which suggests that board independence facilitates the incorporation of short sellers' important adverse information in managerial decision making. In consistence with existing studies that firm size, R\&D expenses, and shortselling constraints can affect the likelihood of equity misvaluation, our results further show that the moderating effect of short selling is more pronounced in smaller firms, in firms 
with lower institutional ownership, and in firms with higher R\&D. Overall, these results suggest that short selling has an offsetting impact on equity market timing for overvalued firms, leading to an increase in leverage. These results do not depend on the definitions of leverage.

Our study examines managerial financing decisions in the presence of short sellers. The results of our study contribute to a better understanding of corporate financing decisions and hold implications for policy makers, managers, shareholders, and academics. The findings that short selling reduces equity market timing of an overvalued firm and thus potentially reduces investment in suboptimal projects indicate important check and balances in the financial markets coming from short selling. Policymakers should consider this market-based disciplinary mechanism of short selling while evaluating any existing or future regulations affecting short selling. The results of this study are particularly important for managers. The results support the argument that high short selling is embedded with important adverse information about firm prospects and that it is important for managers to incorporate this information into their decision making. This study also encourages shareholders to ensure an independent board so that the important adverse information coming from short selling is effectively incorporated into management decision making. Finally, the interesting results of this study are expected to motivate further academic research linking capital structure to other branches of literature including short selling and governance. 
Table 1.1 Summary Statistics

Panel A provides descriptive statistics of our dependent and independent variables, and Panel B shows the Pearson's Correlation Coefficients. $B L$ is book leverage; $M L$ is market leverage; $S I$ is the short interest; $\triangle S I$ is changes in short interest; $V P$ is value-to-price; $M B$ is market-to-book ratio; PPE is property, plant \& equipment; $E B I T D$ is earnings before interest, taxes, and depreciation; $S E$ is selling expenses; $R \& D$ is research and development expenses, and Size is firm size. The Appendix includes the detailed definitions of all these variables. The sources of the data are Compustat and CRSP. The sample period is from the fiscal year 1974 to 2014 and contains 26,270 firm-year observations. Statistical significance at $1 \%, 5 \%$, and $10 \%$ is indicated as ${ }^{* * *}, * *$, and ${ }^{*}$, respectively.

Panel A: Descriptive Statistics

\begin{tabular}{cccccc}
\hline Variable & Mean & Std. Dev. & $25 \mathrm{P}$ & $50 \mathrm{P}$ & $75 \mathrm{P}$ \\
\hline$B L$ & 0.213 & 0.168 & 0.068 & 0.202 & 0.319 \\
$M L$ & 0.162 & 0.152 & 0.036 & 0.130 & 0.243 \\
$S I$ & 0.035 & 0.048 & 0.004 & 0.017 & 0.046 \\
$\Delta S I$ & $(0.018)$ & 1.045 & $(0.247)$ & $(0.007)$ & 0.208 \\
$V P$ & 0.495 & 0.498 & 0.244 & 0.456 & 0.662 \\
$M B$ & 1.735 & 1.009 & 1.108 & 1.428 & 2.001 \\
$P P E$ & 0.299 & 0.218 & 0.129 & 0.250 & 0.417 \\
$E B I T D$ & 0.137 & 0.095 & 0.090 & 0.136 & 0.187 \\
$S E$ & 0.243 & 0.217 & 0.115 & 0.201 & 0.317 \\
$R \& D$ & 0.041 & 0.336 & - & 0.003 & 0.035 \\
Size & 6.775 & 1.655 & 5.607 & 6.717 & 7.880 \\
\hline
\end{tabular}

Panel B: Pearson's Correlation

\begin{tabular}{|c|c|c|c|c|c|c|c|c|}
\hline & $B L$ & $M L$ & $S I$ & $\Delta S I$ & $V P$ & $M B$ & $P P E$ & EBIT \\
\hline$M L$ & $0.89 * * *$ & & & & & & & \\
\hline$S I$ & $0.08 * * *$ & $0.08 * * *$ & & & & & & \\
\hline$\Delta S I$ & $0.02 * * *$ & $0.01 * *$ & $0.35 * * *$ & & & & & \\
\hline$V P$ & $0.12 * * *$ & $0.19 * * *$ & $-0.01 * *$ & $0.01 * *$ & & & & \\
\hline$M B$ & $-0.23 * * *$ & $-0.40 * * *$ & $0.07 * * *$ & 0.01 & $-0.21 * * *$ & & & \\
\hline$P P E$ & $0.31 * * *$ & $0.29 * * *$ & 0.00 & 0.00 & $0.01 *$ & $-0.13 * * *$ & & \\
\hline EBITD & $-0.04 * * *$ & $-0.15 * * *$ & -0.01 & $0.03 * * *$ & $0.07 * * *$ & $0.36 * * *$ & $0.19^{* * *}$ & \\
\hline$S E$ & $-0.21 * * *$ & $-0.24 * * *$ & $0.03 * * *$ & -0.01 & $-0.19 * * *$ & $0.25 * * *$ & $-0.32 * * *$ & $-0.35 * * *$ \\
\hline$R \& D$ & $-0.07 * * *$ & $-0.07 * * *$ & $0.02 * * *$ & 0.00 & $-0.08 * * *$ & $0.08 * * *$ & $-0.09 * * *$ & $-0.21 * * *$ \\
\hline Size & $0.21 * * *$ & $0.10 * * *$ & $0.04 * * *$ & 0.00 & $0.02 * * *$ & $0.02 * * *$ & $0.11 * * *$ & $0.27 * * *$ \\
\hline
\end{tabular}


Table 1.2 Impact of Short Selling on Book Leverage

This table shows the results of regressing book leverage on various explanatory variables. $B L$ is book leverage; $V P$ is value-to-price; VPDummy is a dummy variable coded one when changes in $V P$ is negative, else zero; $\triangle S I$ is changes in short interest; SIDummy is a dummy variable coded one when $\triangle S I$ is positive, else zero; $M B$ is the market-to-book ratio; INTERACT is an interaction term among $\triangle V P$ Dummy, $\triangle S I D u m m y$, and $\triangle S I ; P P E$ is the property, plant \& equipment; EBITD is earnings before interest, taxes, and depreciation; $S E$ is selling expenses; $R \& D$ is research and development expenses; $R \& D D$ ummy is a dummy variable coded one if the firm has no $R \& D$ expenses, else zero, and Size is firm size. The sample period is from the fiscal year 1974 to 2014. $t$ - Statistics are reported in brackets. Two-sided statistical significance at $1 \%, 5 \%$, and $10 \%$ is indicated as ${ }^{* * *},{ }^{* *}$, and *, respectively.

\begin{tabular}{|c|c|}
\hline Explanatory Variables & $B L$ \\
\hline INTERACT $T_{i, t-1}$ & $\begin{array}{c}0.014 \\
{[5.14]^{* * *}}\end{array}$ \\
\hline$\Delta S I_{i, t-1}$ & $\begin{array}{c}-0.002 \\
{[-2.15]^{* *}}\end{array}$ \\
\hline SIDummy $_{i, t-1}$ & $\begin{array}{c}0.006 \\
{[3.85]^{* * *}}\end{array}$ \\
\hline VPDummy $y_{i, t-1}$ & $\begin{array}{c}-0.007 \\
{[-3.52]}\end{array}$ \\
\hline$M B_{i, t-1}$ & $\begin{array}{c}-0.017 \\
{[-7.61] * * *}\end{array}$ \\
\hline$P P E_{i, t-1}$ & $\begin{array}{c}0.145 \\
{[7.24]^{* * *}}\end{array}$ \\
\hline$E B I T D_{i, t-1}$ & $\begin{array}{c}-0.233 \\
{[-8.98] * * *}\end{array}$ \\
\hline$S E_{i, t-1}$ & $\begin{array}{c}-0.057 \\
{[-4.06]^{* * *}}\end{array}$ \\
\hline$R \& D_{i, t-1}$ & $\begin{array}{c}0.002 \\
{[0.75]}\end{array}$ \\
\hline$R \& D D u m m y_{i, t-1}$ & $\begin{array}{c}0.021 \\
{[2.80]^{* * *}}\end{array}$ \\
\hline$S i z e_{i, t-1}$ & $\begin{array}{c}0.021 \\
{[8.05]^{* * *}}\end{array}$ \\
\hline Constant & $\begin{array}{c}0.100 \\
{[5.49]^{* * *}}\end{array}$ \\
\hline $\begin{array}{l}\text { Observations } \\
\text { Adjusted } R \text {-squared } \\
\text { Industry FE }\end{array}$ & $\begin{array}{c}26,270 \\
0.351 \\
\text { YES }\end{array}$ \\
\hline
\end{tabular}


Table 1.3 Impact of Short Selling on Book Leverage and Board Independence

This table shows the results of regressing book leverage on various explanatory variables. $B L$ is book leverage; $V P$ is value-to-price; VPDummy is a dummy variable coded one when changes in $V P$ is negative, else zero; $\Delta S I$ is changes in short interest; SIDummy is a dummy variable coded one when $\triangle S I$ is positive, else zero; $M B$ is the market-to-book ratio; INTERACT is an interaction term among $\triangle V P$ Dummy, $\triangle S I D u m m y$, and $\triangle S I ; P P E$ is the property, plant \& equipment; $E B I T D$ is earnings before interest, taxes, and depreciation; $S E$ is selling expenses; $R \& D$ is research and development expenses; $R \& D D u m m y$ is a dummy variable coded one if the firm has no $R \& D$ expenses, else zero, and Size is firm size. The sample period is from the fiscal year 1974 to 2014. $t$ - Statistics are reported in brackets. Two-sided statistical significance at $1 \%, 5 \%$, and $10 \%$ is indicated as ${ }^{* * *},{ }^{* *}$, and *, respectively.

\begin{tabular}{|c|c|c|}
\hline \multirow{2}{*}{$\begin{array}{l}\text { Explanatory } \\
\text { Variables }\end{array}$} & \multicolumn{2}{|c|}{ Dependent Variable: $B L$} \\
\hline & Non-Independent Board & Independent Board \\
\hline \multirow{2}{*}{$I N T E R A C T_{i, t-1}$} & -0.015 & 0.016 \\
\hline & {$[-1.15]$} & {$[2.83]^{* * *}$} \\
\hline \multirow[t]{2}{*}{$\Delta S I_{i, t-1}$} & 0.007 & -0.002 \\
\hline & {$[1.99] * *$} & {$[-0.75]$} \\
\hline \multirow[t]{2}{*}{ SIDummy $y_{i, t-1}$} & 0.000 & 0.011 \\
\hline & {$[0.01]$} & {$[4.26] * * *$} \\
\hline \multirow[t]{2}{*}{ VPDummy $y_{i, t-1}$} & -0.007 & -0.007 \\
\hline & {$[-1.07]$} & {$[-2.82] * * *$} \\
\hline \multirow[t]{2}{*}{$M B_{i, t-1}$} & -0.015 & -0.015 \\
\hline & {$[-1.60]$} & {$[-4.85]^{* * *}$} \\
\hline \multirow[t]{2}{*}{$P P E_{i, t-1}$} & 0.112 & 0.110 \\
\hline & {$[1.68]^{*}$} & {$[3.47]^{* * *}$} \\
\hline \multirow[t]{2}{*}{$E_{B I T D_{i, t-1}}$} & -0.320 & -0.172 \\
\hline & {$[-2.39] * *$} & {$[-3.70] * * *$} \\
\hline \multirow[t]{2}{*}{$S E_{i, t-1}$} & -0.182 & -0.015 \\
\hline & {$[-1.51]$} & {$[-0.39]$} \\
\hline \multirow[t]{2}{*}{$R \& D_{i, t-1}$} & -0.354 & -0.019 \\
\hline & {$[-0.96]$} & {$[-0.97]$} \\
\hline \multirow[t]{2}{*}{$R \& D D u m m y_{i, t-1}$} & 0.022 & 0.024 \\
\hline & {$[0.90]$} & {$[1.89]^{*}$} \\
\hline \multirow[t]{2}{*}{$\operatorname{Size}_{i, t-1}$} & 0.022 & 0.020 \\
\hline & {$[1.71]^{*}$} & {$[4.66]^{* * *}$} \\
\hline \multirow[t]{2}{*}{ Constant } & 0.083 & 0.045 \\
\hline & {$[0.80]$} & [1.38] \\
\hline Observations & 1,331 & 10,214 \\
\hline Adjusted R-squared & 0.619 & 0.402 \\
\hline Industry $F E$ & YES & YES \\
\hline
\end{tabular}


Table 1.4 Impact of Short Selling on Book Leverage and Firm Size

This table shows the results of regressing book leverage in Low, Medium, and High firm size groups. $B L$ is book leverage; $V P$ is value-to-price; VPDummy is a dummy variable coded one when changes in $V P$ is negative, else zero; $\Delta S I$ is changes in short interest; SIDummy is a dummy variable coded one when $\triangle S I$ is positive, else zero; $M B$ is the marketto-book ratio; INTERACT is an interaction term among $\triangle V P D u m m y, \triangle S I D u m m y$, and $\triangle S I$; $P P E$ is the property, plant \& equipment; EBITD is earnings before interest, taxes, and depreciation; $S E$ is selling expenses; $R \& D$ is research and development expenses; $R \& D D u m m y$ is a dummy variable coded one if the firm has no $R \& D$ expenses, else zero, and Size is firm size. The sample period is from the fiscal year 1974 to 2014. Two-sided statistical significance at $1 \%, 5 \%$, and $10 \%$ is indicated as $* * *, * *$, and $*$, respectively.

\begin{tabular}{|c|c|c|c|}
\hline \multirow{2}{*}{$\begin{array}{l}\text { Explanatory } \\
\text { Variables }\end{array}$} & \multicolumn{3}{|c|}{ Dependent Variable: $B L$} \\
\hline & Low & Medium & High \\
\hline \multirow[t]{2}{*}{$I N T E R A C T_{i, t-1}$} & 0.019 & 0.009 & 0.010 \\
\hline & {$[2.58] * *$} & {$[3.10]^{* * *}$} & {$[2.08] * *$} \\
\hline \multirow[t]{2}{*}{$\Delta S I_{i, t-1}$} & -0.002 & -0.002 & -0.002 \\
\hline & {$[-0.64]$} & {$[-1.17]$} & {$[-1.22]$} \\
\hline \multirow[t]{2}{*}{ SIDummy $_{i, t-1}$} & 0.001 & 0.011 & 0.009 \\
\hline & {$[0.30]$} & {$[3.25]^{* * *}$} & {$[4.24]^{* * *}$} \\
\hline \multirow[t]{2}{*}{ VPDummy $y_{i, t-1}$} & -0.004 & -0.010 & -0.006 \\
\hline & {$[-0.97]$} & {$[-3.68] * * *$} & {$[-2.51]^{* *}$} \\
\hline \multirow[t]{2}{*}{$M B_{i, t-1}$} & -0.025 & -0.020 & -0.006 \\
\hline & {$[-5.05] * * *$} & {$[-5.08] * * *$} & {$[-2.40]^{* *}$} \\
\hline \multirow[t]{2}{*}{$P P E_{i, t-1}$} & 0.235 & 0.152 & 0.074 \\
\hline & {$[5.71] * * *$} & {$[4.76]^{* * *}$} & {$[2.86]^{* * *}$} \\
\hline \multirow[t]{2}{*}{$E B I T D_{i, t-1}$} & -0.062 & -0.276 & -0.373 \\
\hline & {$[-1.82]^{*}$} & {$[-6.30] * * *$} & {$[-9.90] * * *$} \\
\hline \multirow[t]{2}{*}{$S E_{i, t-1}$} & 0.002 & -0.034 & -0.013 \\
\hline & {$[0.12]$} & {$[-1.51]$} & {$[-0.27]$} \\
\hline \multirow[t]{2}{*}{$R \& D_{i, t-1}$} & 0.004 & 0.001 & -0.045 \\
\hline & {$[2.03] * *$} & {$[0.32]$} & {$[-1.00]$} \\
\hline \multirow[t]{2}{*}{$R \& D D u m m y_{i, t-1}$} & 0.009 & 0.018 & 0.015 \\
\hline & {$[0.64]$} & {$[1.72]^{*}$} & {$[1.34]$} \\
\hline \multirow[t]{2}{*}{$S i z e_{i, t-1}$} & 0.043 & 0.038 & 0.016 \\
\hline & {$[8.20] * * *$} & {$[8.72]^{* * *}$} & {$[3.17]^{* * *}$} \\
\hline \multirow[t]{2}{*}{ Constant } & 0.092 & 0.030 & 0.067 \\
\hline & {$[2.87]^{* * *}$} & {$[0.91]$} & {$[1.24]$} \\
\hline Observations & 6,275 & 9,322 & 10,672 \\
\hline Adjusted R-squared & 0.466 & 0.430 & 0.387 \\
\hline Industry FE & YES & YES & YES \\
\hline
\end{tabular}


Table 1.5 Impact of Short Selling on Book Leverage and Institutional Ownership

This table shows the results of regressing book leverage in Low, Medium, and High institutional ownership firms. $B L$ is book leverage; $V P$ is value-to-price; VPDummy is a dummy variable coded one when changes in $V P$ is negative, else zero; $\Delta S I$ is changes in short interest; SIDummy is a dummy variable coded one when $\triangle S I$ is positive, else zero; $M B$ is the market-to-book ratio; INTERACT is an interaction term among $\triangle V P D u m m y$, $\triangle S I D u m m y$, and $\triangle S I ; P P E$ is the property, plant \& equipment; EBITD is earnings before interest, taxes, and depreciation; $S E$ is selling expenses; $R \& D$ is research and development expenses; $R \& D D$ ummy is a dummy variable coded one if the firm has no $R \& D$ expenses, else zero, and Size is firm size. The sample period is from the fiscal year 1974 to 2014. Two-sided statistical significance at $1 \%, 5 \%$, and $10 \%$ is indicated as $* * *, * *$, and $*$, respectively.

\begin{tabular}{|c|c|c|c|}
\hline \multirow{2}{*}{$\begin{array}{l}\text { Explanatory } \\
\text { Variables }\end{array}$} & \multicolumn{3}{|c|}{ Dependent Variable: $B L$} \\
\hline & Low & Medium & High \\
\hline \multirow{2}{*}{ INTERACT $T_{i, t-1}$} & 0.022 & 0.024 & 0.005 \\
\hline & {$[3.50] * * *$} & {$[4.66] * * *$} & [1.09] \\
\hline \multirow{2}{*}{$\Delta S I_{i, t-1}$} & -0.006 & -0.005 & 0.005 \\
\hline & {$[-2.06]^{* *}$} & {$[-2.34] * *$} & {$[2.85]^{* * *}$} \\
\hline \multirow{2}{*}{ SIDummy $_{i, t-1}$} & 0.001 & 0.006 & 0.006 \\
\hline & {$[0.20]$} & {$[1.85]^{*}$} & {$[2.06]^{* *}$} \\
\hline \multirow[t]{2}{*}{ VPDummy $y_{i, t-1}$} & -0.007 & -0.007 & -0.005 \\
\hline & {$[-1.54]$} & {$[-2.62] * * *$} & {$[-1.85]^{*}$} \\
\hline \multirow[t]{2}{*}{$M B_{i, t-1}$} & -0.021 & -0.018 & -0.014 \\
\hline & {$[-6.89] * * *$} & {$[-5.67]^{* * *}$} & {$[-3.34]^{* * *}$} \\
\hline \multirow[t]{2}{*}{$P P E_{i, t-1}$} & 0.213 & 0.142 & 0.098 \\
\hline & {$[6.35] * * *$} & {$[4.63] * * *$} & {$[3.07] * * *$} \\
\hline \multirow[t]{2}{*}{$E B I T D_{i, t-1}$} & -0.193 & -0.206 & -0.254 \\
\hline & {$[-5.20]^{* * *}$} & {$[-5.59]^{* * *}$} & {$[-5.42]^{* * *}$} \\
\hline \multirow[t]{2}{*}{$S E_{i, t-1}$} & -0.041 & -0.042 & -0.062 \\
\hline & {$[-1.81]^{*}$} & {$[-2.66] * * *$} & {$[-1.74]^{*}$} \\
\hline \multirow[t]{2}{*}{$R \& D_{i, t-1}$} & 0.010 & -0.001 & -0.001 \\
\hline & {$[2.59] * * *$} & {$[-0.41]$} & {$[-0.15]$} \\
\hline \multirow[t]{2}{*}{$R \& D D u m m y_{i, t-1}$} & 0.016 & 0.031 & 0.019 \\
\hline & [1.01] & {$[3.13] * * *$} & {$[1.71]^{*}$} \\
\hline \multirow[t]{2}{*}{$\operatorname{Size}_{i, t-1}$} & 0.029 & 0.023 & 0.015 \\
\hline & {$[9.87] * * *$} & {$[5.56] * * *$} & {$[3.61]^{* * *}$} \\
\hline \multirow[t]{2}{*}{ Constant } & 0.139 & 0.036 & 0.120 \\
\hline & {$[5.89]^{* * *}$} & [1.26] & {$[3.06] * * *$} \\
\hline Observations & 6,072 & 8,907 & 9,180 \\
\hline Adjusted R-squared & 0.474 & 0.399 & 0.399 \\
\hline Industry FE & YES & YES & YES \\
\hline
\end{tabular}


Table 1.6 Impact of Short Selling on Book Leverage and $R \& D$

This table shows the results of regressing book leverage in Low, Medium, and High $R \& D$ firms. $B L$ is book leverage; $V P$ is value-to-price; VPDummy is a dummy variable coded one when changes in $V P$ is negative, else zero; $\Delta S I$ is changes in short interest; SIDummy is a dummy variable coded one when $\triangle S I$ is positive, else zero; $M B$ is the market-to-book ratio; INTERACT is an interaction term among $\triangle V P D$ Dmmy, $\triangle$ SIDummy, and $\triangle S I ; P P E$ is the property, plant \& equipment; EBITD is earnings before interest, taxes, and depreciation; $S E$ is selling expenses; $R \& D$ is research and development expenses; $R \& D D$ Dmmy is a dummy variable coded one if the firm has no $R \& D$ expenses, else zero, and Size is firm size. The sample period is from the fiscal year 1974 to 2014. Two-sided statistical significance at $1 \%, 5 \%$, and $10 \%$ is indicated as $* * *, * *$, and $*$, respectively.

\begin{tabular}{|c|c|c|c|}
\hline \multirow{2}{*}{$\begin{array}{l}\text { Explanatory } \\
\text { Variables }\end{array}$} & \multicolumn{3}{|c|}{ Dependent Variable: $B L$} \\
\hline & Low & Medium & High \\
\hline \multirow[t]{2}{*}{$I N T E R A C T_{i, t-1}$} & 0.006 & 0.019 & 0.017 \\
\hline & {$[1.07]$} & {$[1.57]$} & {$[1.99] * *$} \\
\hline \multirow[t]{2}{*}{$\Delta S I_{i, t-1}$} & -0.004 & -0.005 & 0.000 \\
\hline & {$[-1.54]$} & {$[-1.08]$} & {$[0.03]$} \\
\hline \multirow[t]{2}{*}{ SIDummy $_{i, t-1}$} & 0.016 & 0.006 & 0.005 \\
\hline & {$[4.41]^{* * *}$} & {$[1.66]^{*}$} & {$[1.23]$} \\
\hline \multirow[t]{2}{*}{ VPDummy $y_{i, t-1}$} & -0.012 & -0.008 & -0.001 \\
\hline & {$[-3.45] * * *$} & {$[-2.01]^{* *}$} & {$[-0.35]$} \\
\hline \multirow{2}{*}{$M B_{i, t-1}$} & -0.004 & 0.018 & -0.010 \\
\hline & {$[-1.05]$} & {$[1.96]^{*}$} & {$[-3.16]^{* * *}$} \\
\hline \multirow[t]{2}{*}{$P P E_{i, t-1}$} & 0.117 & 0.019 & 0.036 \\
\hline & {$[2.88] * * *$} & {$[0.30]$} & {$[0.92]$} \\
\hline \multirow[t]{2}{*}{$E B I T D_{i, t-1}$} & -0.417 & -0.490 & -0.305 \\
\hline & {$[-9.11]^{* * *}$} & {$[-5.81] * * *$} & {$[-3.73] * * *$} \\
\hline \multirow[t]{2}{*}{$S E_{i, t-1}$} & 0.003 & 0.216 & -0.097 \\
\hline & {$[0.06]$} & {$[1.92]^{*}$} & {$[-1.06]$} \\
\hline \multirow[t]{2}{*}{$R \& D_{i, t-1}$} & 35.748 & 1.663 & 0.053 \\
\hline & {$[13.15]^{* * *}$} & [1.21] & {$[1.28]$} \\
\hline \multirow[t]{2}{*}{$R \& D D u m m y_{i, t-1}$} & 0.129 & 0.044 & \\
\hline & {$[4.93] * * *$} & {$[0.48]$} & \\
\hline \multirow[t]{2}{*}{$\operatorname{Size}_{i, t-1}$} & 0.014 & 0.021 & 0.013 \\
\hline & {$[1.68]^{*}$} & {$[2.30]^{* *}$} & {$[2.03] * *$} \\
\hline \multirow[t]{2}{*}{ Constant } & 0.175 & 0.041 & 0.113 \\
\hline & {$[2.45]^{* *}$} & {$[0.53]$} & {$[1.37]$} \\
\hline Observations & 4,354 & 2,430 & 3,888 \\
\hline Adjusted R-squared & 0.494 & 0.419 & 0.298 \\
\hline Industry FE & YES & YES & YES \\
\hline
\end{tabular}


Table 1.7 Impact of Short Selling on Book Leverage (Total Liabilities)

This table shows the results of regressing book leverage on various explanatory variables. $B L$ is book leverage; $V P$ is value-to-price; VPDummy is a dummy variable coded one when changes in $V P$ is negative, else zero; $\triangle S I$ is changes in short interest; SIDummy is a dummy variable coded one when $\triangle S I$ is positive, else zero; $M B$ is the market-to-book ratio; INTERACT is an interaction term among $\triangle V P D$ Dmmy, $\triangle S I D u m m y$, and $\triangle S I ; P P E$ is the property, plant \& equipment; EBITD is earnings before interest, taxes, and depreciation; $S E$ is selling expenses; $R \& D$ is research and development expenses; $R \& D D u m m y$ is a dummy variable coded one if the firm has no $R \& D$ expenses, else zero, and Size is firm size. The sample period is from the fiscal year 1974 to 2014. Two-sided statistical significance at $1 \%, 5 \%$, and $10 \%$ is indicated as $* * *, * *$, and $*$, respectively.

\begin{tabular}{|c|c|}
\hline Explanatory Variables & $B L$ \\
\hline \multirow[t]{2}{*}{$I_{N T E R A C T} T_{i, t-1}$} & 0.013 \\
\hline & {$[5.31] * * *$} \\
\hline \multirow[t]{2}{*}{$\Delta S I_{i, t-1}$} & -0.001 \\
\hline & {$[-1.10]$} \\
\hline \multirow{2}{*}{ SIDummy $_{i, t-1}$} & 0.004 \\
\hline & {$[2.21] * *$} \\
\hline \multirow{2}{*}{ VPDummy $y_{i, t-1}$} & -0.009 \\
\hline & {$[-4.79] * * *$} \\
\hline \multirow[t]{2}{*}{$M B_{i, t-1}$} & -0.010 \\
\hline & {$[-3.61] * * *$} \\
\hline \multirow[t]{2}{*}{$P P E_{i, t-1}$} & 0.132 \\
\hline & {$[5.55]^{* * *}$} \\
\hline \multirow[t]{2}{*}{$E B I T D_{i, t-1}$} & -0.406 \\
\hline & {$[-13.27]^{* * *}$} \\
\hline \multirow[t]{2}{*}{$S E_{i, t-1}$} & -0.059 \\
\hline & {$[-3.22] * * *$} \\
\hline \multirow{2}{*}{$R \& D_{i, t-1}$} & 0.012 \\
\hline & {$[2.25]^{* *}$} \\
\hline \multirow[t]{2}{*}{$R \& D D u m m y_{i, t-1}$} & -0.003 \\
\hline & {$[-0.36]$} \\
\hline \multirow[t]{2}{*}{$\operatorname{Size}_{i, t-1}$} & 0.045 \\
\hline & {$[14.91] * * *$} \\
\hline \multirow[t]{2}{*}{ Constant } & 0.237 \\
\hline & {$[11.08]^{* * *}$} \\
\hline Observations & 26,270 \\
\hline Adjusted R-squared & 0.398 \\
\hline Industry $F E$ & YES \\
\hline
\end{tabular}




\section{CHAPTER 2: DOES BOARD INDEPENDENCE REDUCE INFORMED SHORT SELLING PRIOR TO EARNINGS ANNOUNCEMENTS?}

\subsection{Introduction}

Short sellers are considered sophisticated investors. Financial theory suggests that short positions should bear a negative relation with stock returns (e.g., Diamond and Verrecchia, 1987). Empirically, the prior literature provides ample evidence that short sellers are generally successful in identifying securities that underperform the market (Asquith and Meulbroek, 1996; Desai, Ramesh, Thiagarajan, and Balachandran, 2002). Past studies also document evidence that short sellers use information in various predictor variables when taking short positions (Dechow, Hutton, Meulbroek, and Sloan, 2001; Drake, Rees, and Swanson, 2011). Other studies argue that short sellers' ability in identifying stocks that underperform in the future can be partially attributed to their possession of private information. For example, Christophe, Ferri, and Angel (2004) examine short selling prior to earnings announcements of Nasdaq-listed firms and show that the pre-announcement short selling mostly appears to be driven by information specific to the upcoming announcements of the individual firms. Anderson, Reeb, and Zhao (2012) investigate the relation between organization structure and the information content of short sales and find that the informed trading via short sales occurs more readily in family firms than in nonfamily firms. These researchers argue that family owners have access to privileged information and may seek to earn profits in light of adverse information. Alternatively, family firms may have a variety of linkages that could facilitate the leakage of material nonpublic information leading to informed trading prior to earnings announcements. 
In light of the above substantial evidence that short sellers are informed traders, and may use privately acquired information in selling short prior to earnings announcement events, an obvious question arises about the effectiveness of corporate boards in protecting the shareholders from the exploitation of short sellers around these events through their access to nonpublic information ${ }^{9}$. Specifically, the board of directors has the fiduciary responsibility to uphold the best interests of the shareholders which requires maintaining an effective information environment surrounding important corporate events like earnings announcements so that informed traders cannot make abnormal returns at the expense of uninformed traders by trading with nonpublic information. Therefore, it is important to examine how corporate boards are impacting short selling behavior driven by possession of nonpublic information which is the focus of this study. With the evidence that independent directors are effective monitors (Fama and Jensen, 1983; Weisbach, 1988; Nguyen and Nielsen, 2010; Byrd and Hickman, 1992), in this paper, we argue that access to nonpublic information will be limited in firms with independent boards which will reduce informed short selling prior to upcoming earnings announcements. Existing literature suggests that board leadership structure may affect the value of board's monitoring activities. For example, Desai, Kroll, and Wright (2003) note that shareholders benefit from the monitoring by independent directors in the presence of CEO duality (when the titles of both the CEO and the Chairman of the Board are assigned to the same

\footnotetext{
${ }^{9}$ Some studies have referred to information not reflected in publicly available data as private information (Christophe, Ferri, and Angel, 2004; Anderson, Reeb, and Zhao, 2012). However, we choose to use nonpublic over private for two reasons; (1) it may be very difficult to isolate private information by a limited set of control variables and (2) short sellers conduct extensive research on firms they target. Therefore, they may have access to some information which is not necessarily obtained through private channels but possibly through their research. Hence, the nonpublic information in this paper refers to information that is available to short sellers either because they have superior research ability or access to private channels.
} 
individual). Therefore, our second hypothesis argues that board independence is more effective in limiting informed short selling in the presence of CEO duality. Finally, because board size can affect the effectiveness of board's monitoring activities, favorably or unfavorably, our third hypothesis argues that the value of board independence in limiting informed short selling varies with board size.

In this paper, we are interested in examining informed short selling based on nonpublic information. Therefore, we first estimate measures of abnormal short selling $(A B S I)$ and unexpected quarterly earnings $(U Q E)$. We estimate $A B S I$ prior to earnings announcements following Christophe, Ferri, and Angel (2004) and estimate UQE, which cannot be readily attributed to publicly available information, following Anderson, Reeb, and Zhao (2012). To measure informed short selling, we construct a dummy variable Prediction, which is coded one when $A B S I$ is positive and $U Q E$ is negative, and zero otherwise, and thus captures when short sellers trade in the right direction relative to movement of UQE post-announcement. Following Shivdasani and Yermack (1999), we construct a dummy variable IndependentBoards, which is coded one if independent directors constitute a majority of the board and zero otherwise. We employ Logistic model to regress Prediction on IndependentBoards after controlling for $U Q E$ and several control variables that past literature finds to be reliable determinants of short selling. The results show that the coefficient estimate of IndependentBoards is negative and significant, which suggests that informed short selling decreases in firms with independent boards relative to firms with non-independent boards, providing support for our first hypothesis. More specifically, the exponentiated coefficient estimate of IndependentBoards, $e^{-0.185}=0.83$, suggests that the predicted odds of correctly predicting the movement of $U Q E$ post- 
announcement in firms with independent boards is 0.83 times that in firms with nonindependent boards. To evaluate our second hypothesis, we divide our sample into two subsamples; (1) one subsample includes the observations with CEO duality (2) the other subsample includes the observations without CEO duality. The results from estimating our model in the above two subsamples separately show that the coefficient estimate of IndependentBoards is negative and significant where CEO duality is present and insignificant where CEO duality is absent, providing support for our second hypothesis. In the subsample of firms with CEO duality, the exponentiated coefficient estimate of IndependentBoards, $e^{-0.292}=0.74$, suggests that the predicted odds of correctly predicting the movement of $U Q E$ post-announcement in firms with independent boards is 0.74 times that in firms with non-independent boards. Moreover, the magnitude of the coefficient estimate of IndependentBoards in the subsample with CEO duality is larger than that in the entire sample $(-0.292$ versus -0.185$)$. We evaluate our third hypothesis by estimating our model separately in two subsamples constructed based on board size; (1) one subsample includes the observations where the board size is small (2) the other subsample includes the observations where the board size is large. We define board size as small if the size of a board is less than the median board size and large, otherwise. The results show that the coefficient estimate of IndependentBoards is negative and significant in firms with large boards and insignificant in firms with small board, suggesting that board independence is more effective in large boards to limit informed short selling prior to earnings announcement. In the subsample of firms with large boards, the exponentiated coefficient estimate of IndependentBoards, $e^{-0.343}=0.71$, means that the predicted odds of correctly predicting the movement of $U Q E$ post-announcement in firms with 
independent boards is 0.71 times that in firms with non-independent boards. Furthermore, the magnitude of the coefficient estimate of IndependentBoards in the subsample with large board is almost twice that in the entire sample $(-0.343$ versus -0.185$)$.

In our analysis, we have used a set of well known control variables that affect short selling to examine how board independence affects informed short selling. However, the board of directors is determined endogenously and the above documented negative relationship between Prediction and IndependentBoards may be driven by unobservable variables affecting both short selling and board independence. The Sarbanes-Oxley Act of 2002 (SOX, hereafter) provides us an excellent opportunity to deal with this issue by introducing an exogenous shock to the extent of representation of independent directors in corporate boards (see e.g., Linck, Netter, and Yang, 2008; Nguyen and Nielsen, 2010). Our analysis shows that informed short selling significantly decreased in firms where the independent directors constituted the majority of the boards after the shock. More specifically, the exponentiated coefficient estimate of Treatment $*$ PostSOX, an interaction term between Treatment and PostSOX identifing the firms where independent directors constituted the majority of the boards after the shock, $e^{-0.483}=0.62$, means that the predicted odds of correctly predicting the movement of $U Q E$ post-announcement after the shock is 0.62 times that before the shock. These results provide reasonable evidence for our central prediction that independent directors limit informed short selling prior to upcoming earnings announcements.

Our study contributes to both governance and short selling literature by examining one of the most important aspects of corporate governance - board independence-within 
the context of short selling. On one hand, past governance studies have thoroughly examined the relations of board independence with firm value (e.g., Nguyen and Nielsen, 2010), monitoring (e.g., Fama and Jensen, 1983), agency problems (e.g., Weisbach, 1988; Byrd and Hickman, 1992), etc. On the other hand, short selling literature has extensively studied the firm fundamental information (e.g., book-to-market ratio, etc.) that short sellers consider prior to short selling. However, we have not found any studies that directly examine if short sellers consider governance-related information, specifically, board independence, prior to short selling. Thus, our paper contributes to addressing a gap in the current literature. The results of our studies have implications for policymakers in their attempt at maintaining transparent financial markets. We also expect our study to lead to future research in this area which will help gain a better understanding of governance and short selling.

\subsection{Literature Review and Development of Hypotheses}

Christophe, Ferri, and Angel (2004) show that short selling prior to quarterly earnings announcements tends to be driven by information specific to those upcoming announcements of the individual firms. In examining the relations between organization structure and the information content of short sales, Anderson, Reeb, and Zhao (2012) find that family-controlled firms, which may have a variety of linkages that could facilitate the leakage of material, nonpublic information, are more exposed to informed trading via short sales. This evidence suggests that some short selling may be driven by possession of nonpublic information and can adversely affect the shareholders of the firm concerned. However, an effective corporate governance mechanism is supposed to maintain good information environment by managing the flow of information from the firm which should 
reduce access to nonpublic information to outsiders such as short sellers. Existing studies suggest that the presence of independent directors in corporate boards contribute to effective governance mechanism through their better monitoring of management, expertise, etc. For example, Fama and Jensen (1983) argue that most independent directors are managers or decision makers at other organizations and they use their directorships to signal their value to the market. Therefore, they have good incentives to provide good monitoring of the management and establish their reputations. Subsequent studies also provide substantial evidence that independent directors are better monitors of management. For example, Weisbach (1988) find that CEO resignations for poor performance are more likely in companies with outsider-dominated boards than for companies with insiderdominated boards. Byrd and Hickman (1992) find that independent directors monitor firm decisions on behalf of shareholders during acquisition process. Alleviating the endogeneity concerns related to appointment and composition of the board of directors, Nguyen and Nielsen (2010) examines stock price reactions to sudden deaths of directors and note that following director death stock prices drop by $0.85 \%$ on average, suggesting that independent directors provide a valuable service to shareholders. The above evidence leads to our first hypothesis:

Hypothesis 1. Independent directors limit informed short selling prior to upcoming earnings announcements.

Board leadership structure may affect the value of board's monitoring activities. One aspect of board leadership structure that has gained immense attention in the governance literature is the assigning of the titles of both the CEO and the Chairman of the 
Board to the same individual, an issue commonly referred to as CEO duality. For example, Jensen (1993) argues that the CEO cannot perform the critical functions of the Chairman, which include overseeing the process of hiring, compensating, evaluating, and firing of the CEO, without personal interest. In consistence with this argument, Desai, Kroll, and Wright (2003) note that shareholders benefit from the monitoring by independent directors in the presence of CEO duality. Specifically, they find that the percentage of independent directors are positively related to firms' acquisition performance in the presence of CEO duality and negatively related in the absence of CEO duality. This leads to our second hypothesis:

Hypothesis 2. The value of board independence in limiting informed short selling is more pronounced in firms with CEO duality.

Existing studies argue that board size affect board's monitoring activities and thus, the information environment. However, these studies provide opposite arguments and evidence. For example, Klein (2002) find that audit committee independence and board size are positively correlated. Anderson, Mansi, and Reeb (2004) argue that larger boards may increase the level of managerial monitoring and enhance the financial accounting process. However, studies arguing for smaller boards point to the potential difficulties in ensuring the quality of board's monitoring of the management, particularly, of the CEO, in a large board. For example, Jensen (1993) argue that it is easy for the CEO to take control of a large board. Yermack (1995) documents an inverse relationship between board size and firm value and suggests that small boards of directors are more effective. This leads to our third hypothesis: 
Hypothesis 3. The value of board independence in limiting informed short selling varies with board size.

\subsection{Data}

For our analysis, we use monthly/bi-monthly short interest data and quarterly fundamental data from Compustat, and market data including price, returns, trading volume, etc. from the Center for Research in Security Prices (CRSP), and director characteristics data from Institutional Shareholder Services (ISS). Our sample spans from 1996 to 2014 but excludes 2007 through 2009 to remove financial crisis period. We limit our analysis to the U.S common stocks (CRSP share codes 10 and 11). We also exclude financial services firms (SIC codes 6000-6999) and regulated utility firms (SIC codes 4900-4999) from our analysis, which finally gives us a sample of 11,303 firm-quarter observations.

\subsection{Methodology}

\subsubsection{Measure of Unexpected Quarterly Earnings ( $U Q E)$}

In this paper, we hypothesize that short seller's ability to correctly predict quarterly earnings will be reduced in firms with independent directors. Our hypothesis is based on the argument that independent directors maintain good information environment which limits access to nonpublic information by the outsiders, such as short sellers, around earnings announcements. Because we are focusing on short selling based on nonpublic information, we first estimate earnings surprises (positive or negative) which cannot be attributed to publicly available information. Following Anderson, Reeb, and Zhao (2012), we obtain unexpected quarterly earnings $(U Q E)$ for each firm as the residual from the following regression: 


$$
E P S_{i, q}=\alpha+\beta_{1} E P S_{i, q-1}+\beta_{2} E P S_{i, q-4}+\beta_{3} E P S_{i, q-8}+\varepsilon_{i, q}
$$

where $i$ indexes firms; EPS is actual earnings per share of the announcement quarter $(q)$, the prior quarter $(q-1)$, one year ago $(q-4)$, and two years ago $(q-8)$.

\subsubsection{Measure of Abnormal Short Interest (ABSI)}

Because we are interested in short selling driven by nonpublic information about upcoming earnings announcements, we focus on abnormal short selling prior to earnings announcements defined as pre-announcement short selling divided by non-announcement short selling, all minus 1. Following Christophe, Ferri, and Angel (2004), we define preannouncement short selling as shares sold short during the five days preceding the earnings announcement and non-announcement short selling as the average shares sold short during the 57 days prior to the five days of the pre-announcement period. Furthermore, following the convention in short selling literature (Dechow, Hutton, Meulbroek, and Sloan, 2001; Asquith, Pathak, and Ritter, 2005; Karpoff and Lou, 2010; Henry, Kisgen, and Wu, 2011; Grullon, Michenaud, and Weston, 2015), we divide a firm's monthly/bi-monthly short interest $(S I)$ by its total shares outstanding to proxy for short selling. Therefore, our measure of abnormal short interest $(A B S I)$ is expressed as below:

$$
A B S I_{i,(t-5 \text { to } t-1)}=\frac{S I_{i,(t-5 \text { to } t-1)}}{S I_{i,(t-62 \text { to } t-6)}}-1
$$

where $t$ indicates the date of earnings announcement for the firm $i$.

\subsubsection{Measure of Informed Short Selling}

In this section, we develop a measure of informed short selling prior to earnings announcements. We construct a dummy variable, Prediction, that captures the movement of $A B S I$ relative to the movement of $U Q E$. If short sellers are able to predict negative $U Q E$, 
then we expect short selling to increase prior to announcements which imply a positive $A B S I$. Therefore, our measure of correct prediction, Prediction, is coded one when $A B S I$ is positive and $U Q E$ is negative, and zero otherwise. Furthermore, we construct another dummy variable IndependentBoards, which is coded one if independent directors constitute a majority of the board and zero otherwise. As per our hypothesis, we expect Prediction to be negatively correlated with IndependentBoards.

\subsubsection{Model Specification and Estimation Procedure}

To evaluate our hypothesis, we regress Prediction on IndependentBoards after controlling for $U Q E$ and several control variables that past literature finds to be reliable determinants of short selling. For example, Diether, Lee, and Werner (2008) show that short selling tends to be higher for large-cap stocks and high market-to-book ratio. So, we control for firm size (Size), defined as the natural log of quarter-end total assets (Anderson, Reeb, and Zhao, 2012), and market-to-book (MB) ratio, defined as the product of shares outstanding and price divided by the book value of total common equity (Dechow, Hutton, Meulbroek, and Sloan, 2001). Less liquid stocks can be costly for short-sellers (Shleifer and Vishny, 1997). So, we control for liquidity (Liquidity) with trading volume measured as the natural logarithmic value of the daily trading volume averaged across all trading days in the quarter (Anderson, Reeb, and Zhao, 2012). To control for the short selling driven by information in transaction data, we use bid-ask spread (Spread), defined as the daily bid price less the daily ask price, divided by the average of the bid price plus the ask price (Anderson, Reeb, and Zhao, 2012). Figlewski (1981) shows that short interest is correlated with the diversity of beliefs. Following Anderson, Reeb, and Zhao (2012), we control for the diversity of beliefs with the standard deviation of analysts' forecasts divided 
by the previous quarter-end stock price (Dispersion) and with the standard deviation of daily stock returns ( $\mathrm{Vol})$. Anderson, Reeb, and Zhao (2012) document that stocks listed on NYSE exhibit less abnormal short sales than stocks listed on other exchanges. Therefore, we include two dummy variables NasdaqDummy and AmexDummy. NasdaqDummy is coded one for stocks listed on the Nasdaq Stock Exchange, and zero otherwise. AmexDummy is coded one for stocks listed on the American Stock Exchange, and zero otherwise. Furthermore, we include dummy variables for each of 48 Fama-French industry to account for industry effects as well as quarter dummy variables to capture time effects resulting in the below model:

$$
\begin{aligned}
& \text { Prediction }_{i,(t-5} \text { to t-1) } \\
& \qquad \begin{array}{l}
=\alpha_{0}+\beta_{1} \text { IndependentBoards }_{i, t-1}+\beta_{2} U Q E_{i, t}+\theta X_{i, t-1} \\
\quad+\delta_{1} \text { IndustryDummy }+\delta_{1} \text { QuarterDummy }+\varepsilon_{i, t}
\end{array}
\end{aligned}
$$

where $t$ indexes time and $i$ indexes firm; Prediction and IndependentBoards are as defined in the previous section; $U Q E$ is unexpected quarterly earnings; IndustryDummy are dummy variables for each of 48 Fama-French industry classifications; QuarterDummy are dummy variables for each calendar quarter; $X$ is a vector of firm characteristics that affect short selling, which includes market-to-book $(M B)$, firm performance (Performance), stock return volatility ( $\mathrm{Vol}$ ), share turnover (Liquidity), bid-ask spread (Spread), and dummy variables for stocks listed on the American Stock Exchange (AmexDummy) and on Nasdaq Stock Market (NasdaqDummy).

In this paper, our objective is to assess whether informed short selling is related to board independence. We construct a dummy variable to measure informed short selling 
which is used as the dependent variable. Therefore, we choose an estimation method that allows for this dummy variable as the dependent variable. We omit usual regression analysis, including linear probability model, because linear functions are inherently unbounded but probabilities are bounded by zero and one. We choose Logistic regression because it solves the problems associated with bounded dependent variable. Logistic regression removes the upper bound by transforming the probability into odds ratio and removes the lower bound by taking the natural logarithmic value of the odds ratio.

\subsubsection{Endogeneity}

In the previous section, we have used a set of well known control variables that affect short selling. However, the board of directors is determined endogenously and relations between Prediction and IndependentBoards may be driven by unobservable variables affecting both short selling and board independence. Therefore, we test our hypothesis by focusing on an exogenous shock to board independence. In particular, we focus on the exogenous shock to corporate governance environment from the passage of SOX, which, among other things, has increased representation of independent directors on corporate boards (e.g., Linck, Netter, and Yang, 2008; Nguyen and Nielsen, 2010). We examine how $U Q E$ is related to Prediction before and after the passage of SOX. We create a dummy variable PostSOX, which is coded one for years after 2001 and zero otherwise, and a dummy variable Treatment, which is coded one for a firm with board having less than $50 \%$ independent directors prior to 2002 . Therefore, the interaction between these two variables, PostSOX * Treatment, will capture how Prediction is related to board independence. We also include the same set of control variables, industry, and time fixed effects resulting in the following model: 


$$
\begin{aligned}
& \text { Prediction } \left._{i,(t-5} \text { to } t-1\right) \\
& =\alpha_{0}+\beta_{1} U Q E_{i, t}+\gamma_{1}(\text { PostSOX } * \text { Treatment })_{t-1} \\
& +\gamma_{2} \text { PostSOX }_{t-1}+\gamma_{3} \text { Treatment }_{i, t-1}+\theta X_{i, t-1} \\
& +\delta_{1} \text { IndustryDummy }+\delta_{1} \text { QuarterDummy }+\varepsilon_{i, t}
\end{aligned}
$$

As per our hypothesis that board independence reduces informed short selling prior to earnings announcements, we expect PostSOX * Treatment to be negatively correlated with Prediction.

\subsection{Results}

\subsubsection{Summary Statistics}

Panel A of Table 2.1 shows the descriptive statistics of our dependent and independent variables. We calculate the statistics after winsorizing the variables at the 1st and 99th percentiles within each calendar quarter to mitigate the impact of outliers. The statistics of the variables in our study are close to the statistics reported in the comparable studies. For example, the mean values of Size, Liquidity, and Spread are 7.77, 13.34, and 0.03 , respectively, which compare closely to $7.69,13.39$, and 0.04 , the mean values of Firm Size, Trading Volume, and Spread, respectively, in Anderson, Reeb, and Zhao (2012).

Panel B shows the Pearson's Correlation Coefficients among the variables in our study. Our measure of abnormal short selling, ABSI, is positively correlated with Performance and negatively correlated with Vol, Dispersion, Liquidity, and Spread. UQE is positively correlated with both Performance and Liquidity and negatively correlated with Vol, Dispersion, and Spread. 


\subsubsection{Informed Short Selling and Board Independence}

Our analysis starts with examining the relations between Prediction and IndependentBoards after controlling for $U Q E$ and various determinants of short selling as per existing literature. Therefore, we estimate equation (3) in the entire sample and present the results in Table 2.2. The results show that the coefficient estimate of IndependentBoards is negative and significant. Because IndependentBoards is a dummy variable coded one if independent directors constitute a majority of the board and zero otherwise, the above evidence suggests that short sellers' correct prediction of the direction of $U Q E$ post-announcement decreases in firms with independent boards relative to firms with non-independent boards, providing support for our first hypothesis. The interpretations of the coefficient estimates in Logistic regression are not as direct as in OLS regression. Logistic regression models the log odds of a positive response (in this case, the probability of correct prediction of the movement of $U Q E$ post-announcement) as a linear combination of the predictor variables. Therefore, for a one unit change in one predictor variable, the difference in log-odds for correct prediction is expected to change by the respective coefficient, given the other variables in the model are held constant. The coefficient estimate of -0.185 of IndependentBoards indicates that the difference in logodds is expected to be 0.185 units lower in firms with independent boards compared to firms with non-independent boards, while holding the other variables constant in the model. We can also interpret the results in terms of odds-ratio by exponentiating the coefficient estimate, $e^{-0.185}=0.83$, which means that the predicted odds of correctly predicting the movement of $U Q E$ post-announcement in firms with independent boards is 0.83 times that in firms with non-independent boards. 


\subsubsection{Informed Short Selling, Board Independence, and CEO Duality}

In our second hypothesis, drawing from the evidence of existing literature that shareholders benefit from the monitoring by independent directors in the presence of CEO duality, we argue that the value of board independence in limiting informed short selling based on nonpublic information is more pronounced in firms with CEO duality. To evaluate this hypothesis, we divide our sample into two subsamples; (1) one subsample includes the observations with CEO duality (2) the other subsample includes the observations without CEO duality. We then estimate equation (3) with Logistic regression in the above two subsamples separately. Table 2.3 includes the results which show that the coefficient estimate of IndependentBoards is negative and significant where CEO duality is present and insignificant where CEO duality is absent, providing support for our second hypothesis. The coefficient estimate of -0.292 of IndependentBoards indicates that the difference in log-odds is expected to be 0.292 units lower in firms with independent boards compared to firms with non-independent boards, while holding the other variables constant in the model. In terms of odds-ratio, the exponentiated coefficient estimate, $e^{-0.292}=0.74$, means that the predicted odds of correctly predicting the movement of $U Q E$ postannouncement in firms with independent boards is 0.74 times that in firms with nonindependent boards. Furthermore, the magnitude of the coefficient estimate of IndependentBoards in the subsample with CEO duality is larger than that in the entire sample $(-0.292$ versus -0.185$)$. These results suggest that board independence is more

effective in firms with CEO duality than in firms without CEO duality to limit informed short selling based on nonpublic information prior to earnings announcement. 


\subsubsection{Informed Short Selling, Board Independence, and Board Size}

In this paper, we point to the evidence in existing literature that increase in board size may be either beneficial or detrimental for shareholders, which implies that board size may either increase or decrease the value of board independence. Thus, in our third hypothesis we argue that the value of board independence in limiting informed short selling varies with board size. To evaluate this hypothesis, as before, we divide our sample into two subsamples; (1) one subsample includes the observations where the board size is small (2) the other subsample includes the observations where the board size is large. We define board size as small if the size of a board is less than the median board size and large otherwise. We estimate equation (3) with Logistic regression in the above two subsamples separately and report the results in Table 2.4. The results show that the coefficient estimate of IndependentBoards is negative and significant in firms with large boards and insignificant in firms with small boards, suggesting that board independence is more effective in large boards to limit informed short selling prior to earnings announcement. In the subsample of firms with large boards, the coefficient estimate of -0.343 of IndependentBoards indicates that the difference in log-odds is expected to be 0.343 units lower in firms with independent boards compared to firms with non-independent boards, while holding the other variables constant in the model. In terms of odds-ratio, the exponentiated coefficient estimate, $e^{-0.343}=0.71$, means that the predicted odds of correctly predicting the movement of $U Q E$ post-announcement in firms with independent boards is 0.71 times that in firms with non-independent boards. Furthermore, the magnitude of the coefficient estimate of IndependentBoards in the subsample with large boards is almost twice that in the entire sample $(-0.343$ versus -0.185$)$. These results suggest that 
board independence is more effective in firms with large boards to limit informed short selling based on nonpublic information prior to earnings announcement.

\subsubsection{Sarbanes-Oxley Act of 2002, Board Independence, and Informed Short Selling}

In this section, we discuss the results of using the exogenous shock to representation of independent directors on corporate boards from the passage of SOX (see e.g., Linck, Netter, and Yang, 2008; Nguyen and Nielsen, 2010) as a quasi-natural experiment to analyze how informed short selling is related to board indepenence. The results of this analysis are reported in Table 2.5. First, the significant positive coefficient of PostSOX, which is a dummy variable coded one for years after 2001 and zero otherwise, indicates that informed short selling generally increased during the post-SOX period. Furthermore, the coefficient of Treatment, which identifies the set of firms having less than 50\% independent directors prior to 2002 , is strongly significant and positive indicating that short sellers generally have better predictive ability in these firms controlling for various firmcharacteristics. Finally, our variable of interest is Treatment $*$ PostSOX, an interaction term between Treatment and PostSOX. This variable identifies the set of firms (among the entire set of Treatment firms) that changed from having less than 50\% independent directors in their boards prior to the passage of SOX to having more than 50\% independent directors in their boards after the passage of SOX. The strongly significant negative coefficient of this variable indicates that informed short selling significantly decreased in firms where the independent directors constituted the majority of the boards after the shock, controlling for various firm-characteristics that affect short selling. The coefficient estimate of -0.483 of Treatment * PostSOX indicates that the difference in log-odds is 0.483 units lower after

the shock. In terms of odds-ratio, the exponentiated coefficient estimate, $e^{-0.483}=0.62$, 
means that the predicted odds of correctly predicting the movement of $U Q E$ postannouncement after the shock is 0.62 times that before the shock. These results provide reasonable evidence for our central prediction that independent directors limit informed short selling prior to upcoming earnings announcements.

\subsection{Conclusion}

In this paper, we examine whether and how board independence affects informed short selling based on nonpublic information prior to upcoming earnings announcements. Drawing on the evidence that independent directors are effective monitors (Fama and Jensen, 1983; Weisbach, 1988; Nguyen and Nielsen, 2010; Byrd and Hickman, 1992), we argue that access to nonpublic information will be limited within firms having independent boards which will reduce informed short selling prior to upcoming earnings announcements. Existing literature suggests that the value of board independence may be more prominent in the presence of CEO duality, which leads to our second hypothesis that board independence is more effective in limiting informed short selling in the presence of CEO duality. Finally, because board size can affect the effectiveness of board's monitoring activities, favorably or unfavorably, our third hypothesis posits that the value of board independence in limiting informed short selling varies with board size. We evaluate our hypotheses by examining the relations between Prediction, a measure of informed short selling, and IndependentBoards, a dummy variable coded one if independent directors constitute a majority of the board and zero otherwise. We emply Logistic model to regress Prediction on IndependentBoards after controlling for $U Q E$ and several control variables that past literature finds to be reliable determinants of short selling. The results show that the coefficient estimate of IndependentBoards is negative and significant, which suggests 
that informed short selling decreases in firms with independent boards relative to firms with non-independent boards, providing support for our first hypothesis. The results from estimating our model separately in firms with CEO duality and without CEO duality show that the coefficient estimate of IndependentBoards is negative and significant where CEO duality is present and insignificant where CEO duality is absent, which supports our second hypothesis. Finally, after estimating our model separately in firms with small boards and large boards, we find that the coefficient estimate of IndependentBoards is negative and significant in firms with large boards and insignificant in firms with small boards, suggesting that board independence is more effective in large boards to limit informed short selling prior to earnings announcement. Because the board of directors is determined endogenously, the above documented negative relationship between Prediction and IndependentBoards may be driven by unobservable variables affecting both short selling and board independence. Therefore, we perform a quasi-natural experiment relying on the exogenous shock to representation of independent directors on corporate boards from the passage of Sarbanes-Oxley Act of 2002. The results show that informed short selling significantly decreased in firms where the independent directors constituted the majority of the boards after the shock.

Our study contributes both to the governance and short selling literature. The findings that board independence reduces informed short selling driven by nonpublic information points to an important oversight role performed by the independent directors of the corporate board. By studying the utility of board independence in the presence of CEO duality and large boards, this paper helps to clarify when shareholders can expect 
board independence to be more beneficial. Finally, by showing that short selling is sensitive to board independence, we contribute to a better understanding of short selling. 
Table 2.1 Summary Statistics

Panel A provides descriptive statistics of our dependent and independent variables and Panel B shows the Pearson's Correlation Coefficients of the variables. ABSI is abnormal short interest; $U Q E$ is unexpected quarterly earnings; MB is market-to-book; Size is firm size; Performance is firm income before extraordinary items; Vol is stock return volatility; Dispersion is dispersion in analysts' forecasts; Liquidity is trading volume; Spread is bid-ask spread; The Appendix includes the detailed definitions of all these variables. The sources of the data are Compustat and CRSP. The sample period is from the calendar year 1996 to 2014 and contains 11,303 firm-quarter observations.

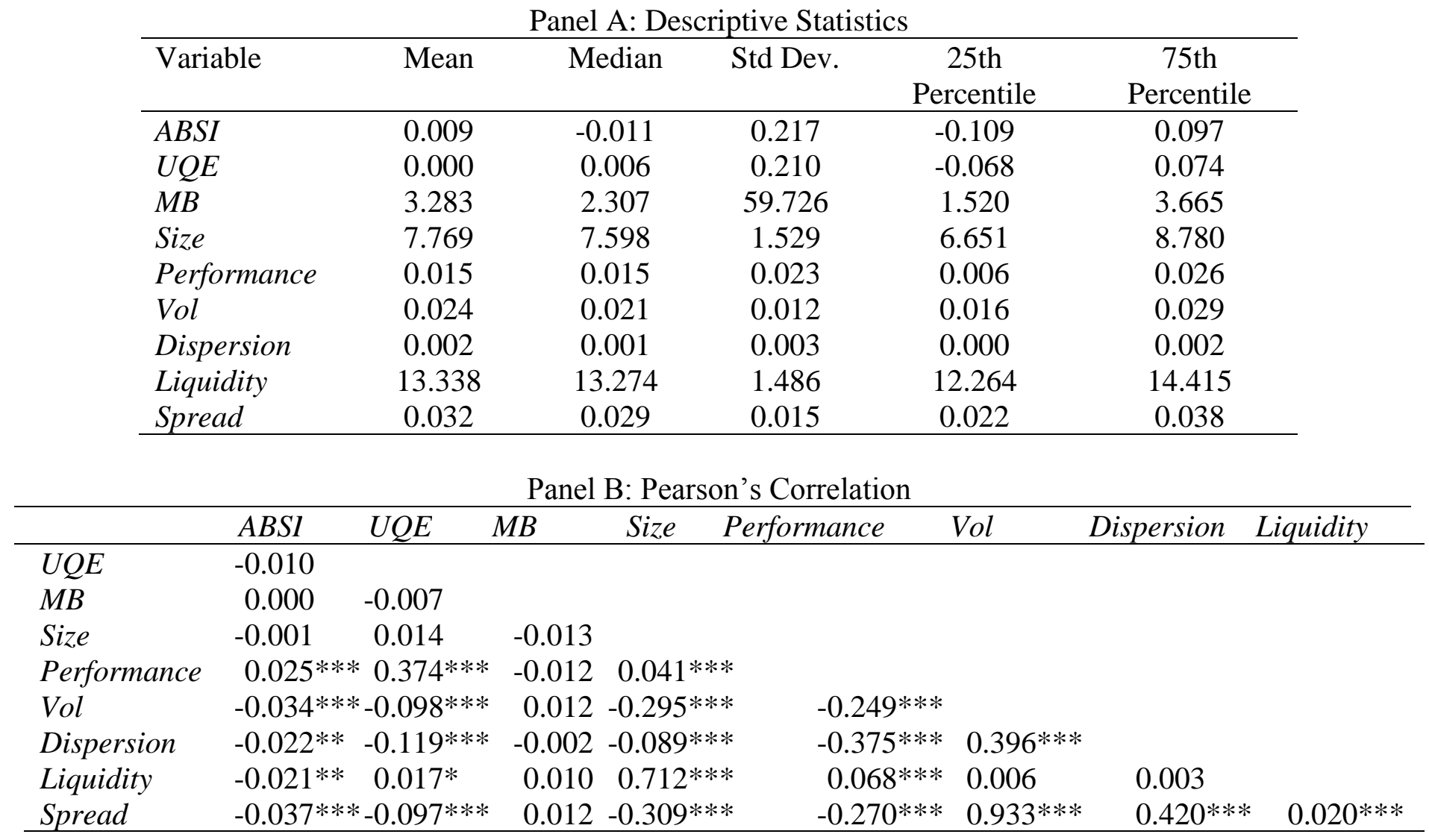


Table 2.2 Informed Short Selling and Board Independence

This table shows the results of regressing Prediction on IndependentBoards controlling for various determinants of short selling using Logistic analytical method. Prediction is a dummy variable coded one when $A B S I$ is positive and $U Q E$ is negative, and zero otherwise. $A B S I$ is abnormal short selling; $U Q E$ is unexpected quarterly earnings; IndependentBoards is a dummy variable coded one if independent directors constitute a majority of the board and zero otherwise; $M B$ is market-to-book; Size is firm size; Performance is firm income before extraordinary items; $\mathrm{Vol}$ is stock return volatility; Dispersion is dispersion in analysts' forecasts; Liquidity is trading volume; Spread is bid-ask spread; AmexDummy is a dummy variable coded one for a stock listed on the American Stock Exchange, and zero otherwise; NasdaqDummy is a dummy variable coded one for a stock listed on the Nasdaq Stock Market, and zero otherwise. The Appendix includes the detailed definitions of all these variables. The sources of the data are Compustat and CRSP. The sample period is from the calendar year 1996 to 2014. t- Statistics are based on standard errors adjusted for serial correlation and heteroskedasticity using the Huber-White sandwich estimator (clustered on firm-level identifier) and are reported in brackets. Two-sided statistical significance at $1 \%, 5 \%$, and $10 \%$ is indicated as $* * *, * *$, and $*$, respectively.

\begin{tabular}{lc}
\hline \multicolumn{2}{c}{ Dependent Variable: Prediction } \\
\hline Explanatory Variables & Coefficients \\
\hline IndependentBoards & -0.185 \\
& {$[-2.26]^{* *}$} \\
UQE & -5.643 \\
& {$[-17.25]^{* * *}$} \\
& -0.000 \\
Size & {$[-0.52]$} \\
& -0.193 \\
Performance & {$[-4.74]^{* * *}$} \\
& -6.807 \\
Vol & {$[-4.73]^{* * *}$} \\
& -9.761 \\
Dispersion & {$[-1.45]$} \\
& -12.700 \\
Liquidity & {$[-0.98]$} \\
\multirow{2}{*}{ Spread } & 0.124 \\
& {$[3.32]^{* * *}$} \\
AmexDummy & -9.964 \\
NasdaqDummy & {$[-1.65]^{*}$} \\
Constant & -0.948 \\
& {$[-1.31]$} \\
& -0.025 \\
& {$[-0.33]$} \\
& -2.189
\end{tabular}




\section{$[-4.41]^{* * *}$}

\begin{tabular}{lc} 
Observations & 11,303 \\
Industry FE & YES \\
Quarter FE & YES \\
Pseudo $R^{2}$ & 0.173 \\
\hline
\end{tabular}


Table 2.3 Informed Short Selling, Board Independence, and CEO Duality

This table shows the results of regressing Prediction on IndependentBoards controlling for various determinants of short selling using Logistic analytical method. Prediction is a dummy variable coded one when $A B S I$ is positive and $U Q E$ is negative, and zero otherwise. $A B S I$ is abnormal short selling; $U Q E$ is unexpected quarterly earnings; IndependentBoards is a dummy variable coded one if independent directors constitute a majority of the board and zero otherwise; $M B$ is market-to-book; Size is firm size; Performance is firm income before extraordinary items; $\mathrm{Vol}$ is stock return volatility; Dispersion is dispersion in analysts' forecasts; Liquidity is trading volume; Spread is bid-ask spread; AmexDummy is a dummy variable coded one for a stock listed on the American Stock Exchange, and zero otherwise; NasdaqDummy is a dummy variable coded one for a stock listed on the Nasdaq Stock Market, and zero otherwise. CEO duality exists when the titles of both the CEO and the Chairman of the Board are assigned to the same individual. The Appendix includes the detailed definitions of all these variables. The sources of the data are Compustat and CRSP. The sample period is from the calendar year 1996 to 2014. t- Statistics are based on standard errors adjusted for serial correlation and heteroskedasticity using the HuberWhite sandwich estimator (clustered on firm-level identifier) and are reported in brackets. Two-sided statistical significance at $1 \%, 5 \%$, and $10 \%$ is indicated as $* * *, * *$, and *, respectively.

\begin{tabular}{lcc}
\hline & Dependent Variable: Prediction \\
\hline Explanatory & \multicolumn{2}{c}{ Coefficients } \\
\cline { 2 - 3 } Variables & With CEO Duality & Without CEO Duality \\
\hline IndependentBoards & -0.292 & 0.012 \\
UQE & {$[-2.82]^{* * *}$} & {$[0.08]$} \\
MB & -5.868 & -5.431 \\
& {$[-13.79]^{* * *}$} & {$[-11.59]^{* * *}$} \\
Size & -0.000 & -0.002 \\
& {$[-0.41]$} & {$[-0.91]$} \\
Performance & -0.188 & -0.169 \\
& {$[-3.48]^{* * *}$} & {$[-2.67]^{* * *}$} \\
Vol & -3.565 & -10.353 \\
& {$[-1.55]$} & {$[-5.27]^{* * *}$} \\
Dispersion & -7.863 & -15.680 \\
& {$[-0.89]$} & {$[-1.51]$} \\
Liquidity & 3.772 & -30.501 \\
\multirow{2}{*}{ Spread } & {$[0.23]$} & {$[-1.66]^{*}$} \\
AmexDummy & 0.080 & 0.168 \\
& {$[1.59]$} & {$[3.02]^{* * *}$} \\
& -14.756 & -3.479 \\
& {$[-1.77]^{*}$} & {$[-0.39]$} \\
& -0.323 &
\end{tabular}




\begin{tabular}{lcc} 
NasdaqDummy & 0.097 & -0.148 \\
Constant & {$[0.91]$} & {$[-1.36]$} \\
& -1.507 & -1.675 \\
& {$[-2.60]^{* * *}$} & {$[-2.55]^{* *}$} \\
Observations & & \\
Industry FE & 6,639 & 4,592 \\
Quarter FE & YES & YES \\
Pseudo $R^{2}$ & YES & YES \\
\hline
\end{tabular}


Table 2.4 Informed Short Selling, Board Independence, and Board Size

This table shows the results of regressing Prediction on IndependentBoards controlling for various determinants of short selling using Logistic analytical method. Prediction is a dummy variable coded one when $A B S I$ is positive and $U Q E$ is negative, and zero otherwise. $A B S I$ is abnormal short selling; $U Q E$ is unexpected quarterly earnings; IndependentBoards is a dummy variable coded one if independent directors constitute a majority of the board and zero otherwise; $M B$ is market-to-book; Size is firm size; Performance is firm income before extraordinary items; $\mathrm{Vol}$ is stock return volatility; Dispersion is dispersion in analysts' forecasts; Liquidity is trading volume; Spread is bid-ask spread; AmexDummy is a dummy variable coded one for a stock listed on the American Stock Exchange, and zero otherwise; NasdaqDummy is a dummy variable coded one for a stock listed on the Nasdaq Stock Market, and zero otherwise. Firms are considered to have small boards if their board size is less than the sample median board size of nine members, otherwise they are considered to have large boards. The Appendix includes the detailed definitions of all these variables. The sources of the data are Compustat and CRSP. The sample period is from the calendar year 1996 to 2014. t- Statistics are based on standard errors adjusted for serial correlation and heteroskedasticity using the Huber-White sandwich estimator (clustered on firm-level identifier) and are reported in brackets. Two-sided statistical significance at $1 \%, 5 \%$, and $10 \%$ is indicated as $* * *, * *$, and $*$, respectively.

\begin{tabular}{lcc}
\hline & Dependent Variable: Prediction \\
\hline Explanatory & \multicolumn{2}{c}{ Coefficients } \\
\cline { 2 - 3 } Variables & Small Board & Large Board \\
\hline IndependentBoards & -0.042 & -0.343 \\
UQE & {$[-0.34]$} & {$[-2.94]^{* * *}$} \\
MB & -6.201 & -5.531 \\
& {$[-13.44]^{* * *}$} & {$[-13.32]^{* * *}$} \\
Size & -0.001 & 0.005 \\
& {$[-1.24]$} & {$[2.71]^{* * *}$} \\
Performance & -0.238 & -0.201 \\
& {$[-3.49]^{* * *}$} & {$[-3.56]^{* * *}$} \\
Vol & -5.726 & -8.522 \\
& {$[-2.91]^{* * *}$} & {$[-4.04]^{* * *}$} \\
Dispersion & 0.103 & -17.465 \\
& {$[0.01]$} & {$[-1.75]^{*}$} \\
Liquidity & -21.863 & -10.887 \\
\multirow{2}{*}{ Spread } & {$[-1.23]$} & {$[-0.56]$} \\
AmexDummy & 0.124 & 0.133 \\
& {$[2.20]^{* *}$} & {$[2.51]^{* *}$} \\
& -14.779 & -5.039 \\
& {$[-1.67]^{*}$} & {$[-0.57]$} \\
& & -0.654 \\
& & {$[-0.89]$}
\end{tabular}




\begin{tabular}{lcc} 
NasdaqDummy & 0.064 & -0.126 \\
& {$[0.58]$} & {$[-1.16]$} \\
Constant & -1.795 & -2.341 \\
& {$[-2.44]^{* *}$} & {$[-3.64]^{* * *}$} \\
& & \\
Observations & 4,413 & 6,849 \\
Industry FE & YES & YES \\
Quarter FE & YES & YES \\
Pseudo $R^{2}$ & 0.184 & 0.184 \\
\hline
\end{tabular}


Table 2.5 Sarbanes-Oxley Act of 2002, Board Independence, and Informed Short Selling

This table reports the results of the quasi-natural experiment with Logistic analytical method using the exogenous shock in board independence from the passage of the Sarbanes-Oxley Act of 2002 (SOX). Prediction is a dummy variable coded one when ABSI is positive and $U Q E$ is negative, and zero otherwise. $A B S I$ is abnormal short selling; $U Q E$ is unexpected quarterly earnings; PostSOX is a dummy variable coded one for years after 2001 and zero otherwise; Treatment is a dummy variable coded one for a firm with board having less than $50 \%$ independent directors prior to 2002; $M B$ is market-to-book; Size is firm size; Performance is firm income before extraordinary items; Vol is stock return volatility; Dispersion is dispersion in analysts' forecasts; Liquidity is trading volume; Spread is bid-ask spread; AmexDummy is a dummy variable coded one for a stock listed on the American Stock Exchange, and zero otherwise; NasdaqDummy is a dummy variable coded one for a stock listed on the Nasdaq Stock Market, and zero otherwise. The sample period is from the calendar year 1996 to 2014 and contains 5,345 firm-quarter observations. $t$ - Statistics are based on standard errors adjusted for serial correlation and heteroskedasticity using the Huber-White sandwich estimator (clustered on firm-level identifier) and are reported in brackets. Two-sided statistical significance at 1\%, 5\%, and $10 \%$ is indicated as $* * *, * *$, and $*$, respectively.

\begin{tabular}{lc}
\hline \multicolumn{2}{c}{ Dependent Variable: Prediction } \\
\hline Explanatory Variables & Coefficients \\
\hline UQE & -5.370 \\
Treatment $x$ PostSOX & {$[-10.96]^{* * *}$} \\
Treatment & -0.483 \\
& {$[-2.73]^{* * *}$} \\
PostSOX & 0.509 \\
& {$[3.64]^{* * *}$} \\
Size & 0.836 \\
& {$[1.67]^{*}$} \\
Performance & -0.147 \\
& {$[-2.02]^{* *}$} \\
Vol & -13.382 \\
& {$[-4.53]^{* * *}$} \\
Dispersion & -17.158 \\
& {$[-1.66]^{*}$} \\
Liquidity & -19.620 \\
Spread & {$[-0.77]$} \\
AmexDummy & 0.052 \\
& {$[0.67]$} \\
& 1.412 \\
& {$[0.15]$} \\
& -0.730 \\
& {$[-1.13]$}
\end{tabular}




\begin{tabular}{lc} 
NasdaqDummy & 0.470 \\
& {$[0.72]$} \\
Constant & -0.594 \\
& {$[-0.96]$} \\
& \\
Observations & 5,340 \\
Industry FE & YES \\
Quarter FE & YES \\
Pseudo $R^{2}$ & 0.185 \\
\hline
\end{tabular}




\section{CHAPTER 3: SHORT POSITIONS AND INVESTMENT RECOMMENDATIONS}

\subsection{Introduction}

Prior studies document that short sellers are generally successful in identifying securities that underperform the market (e.g., Seneca, 1967; Figlewski, 1981; Senchack and Starks, 1993; Asquith and Muelbrook, 1996; Desai, Ramesh, Thiagarajan, and Balachandran, 2002; Diether, Lee, and Werner, 2009). Some of these studies focus on informed short selling around quarterly earnings announcement and find preannouncement short selling to be significantly related to post-announcement returns (e.g., Christophe, Ferri, and Angel, 2004; Anderson, Reeb, and Zhao, 2012; Fang, Huang, and Karpoff, 2016). In this paper, drawing on the above evidence of informed short selling around earnings announcement, we provide a methodology that examines preannouncement short selling and provides specific "Sell" recommendations ahead of earnings announcement. Thus, our study provides an important decision support tool to be used in conjunction with the traditional investment recommendations of financial analysts. Recent studies suggest that following sell-side financial analysts' recommendations blindly can be costly for investors as these recommendations can be affected by the economic incentives of these analysts in recommending certain stocks including "growth" stocks, etc. (e.g., Jegadeesh, Kim, Krische, and Lee, 2004). However, the investment recommendations coming from short selling does not suffer from this potential conflict of interest as short sellers undertake significant risk in short selling by investing their own capital (e.g., Drake, Rees, and Swanson, 2011). Furthermore, Drake, Rees, and Swanson (2011) show that when short sellers and financial analysts disagree in their prediction of future returns, investing following the short sellers is the most profitable investment 
strategy. Therefore, our study makes a significant contribution by providing a framework that supports informed decision making.

Our methodology involves examining the short selling of a firm at a point of time closest to its day of quarterly earnings announcements. Following the convention in the short selling literature (e.g., Dechow, Hutton, Meulbroek, and Sloan, 2001; Asquith, Pathak, and Ritter, 2005; Karpoff and Lou, 2010; Henry, Kisgen, and Wu, 2011; Grullon, Michenaud, and Weston, 2015), we divide a firm's monthly/bi-monthly short interest $(S I)^{10}$ by its total shares outstanding to proxy for short selling. We form quintile portfolios based on SI on the SI publication date ${ }^{11}$ and make "Sell" recommendations for firms in the quintile with the highest SI. We evaluate the effectiveness of our methodology by examining the raw, excess, and abnormal returns of equal-weighted "Sell" portfolios over a long range of holding periods, namely from the one-day holding period to the 30 -day holding period, from the day immediately after the earnings announcement. The results show that raw, excess, and abnormal returns are highly significant up to the 22-day holding period. Furthermore, the returns are larger negative for longer holding periods. For example, the one-day and 14-day holding period raw returns are $-0.24 \%$ and $-0.45 \%$, excess returns are $-0.25 \%$ and $-0.54 \%$, and abnormal returns are $-0.14 \%$ and $-0.48 \%$, respectively. These returns are economically significant considering the "Sell" portfolios are formed on every SI publication date which occurs at a frequency of two every month since September 2007.

\footnotetext{
${ }^{10}$ Short interest is the quantity of firm shares that investors have sold short but not yet covered or closed out.

11 Section 4. Methodology discusses the timeline of short interest data and defines SI publication date which accounts for the lag between a firm's reporting of short interest data and publication of the data upon compilation.
} 
Therefore, focusing on the 14-day holding period, the holding period up to which all returns seem to decrease (that is, the returns become larger negative) as the holding period increases, the annualized simple raw returns and abnormal returns are $-10.80 \%$ and $11.52 \%$. We compute the returns by multiplying the 14-day holding period returns by 24 as there are 24 SI publication dates in a year which mean "Sell" portfolios can also be formed 24 times in a year. We evaluate the robustness of our results though subsample analysis which shows that the results are very significant and consistent for the most recent time in the sample, specifically, from 2010 to 2015 , which points to the relevance of our methodology.

\subsection{Literature Review}

During the last several years, financial researchers have conducted a critical review of the value addition from the analysts' recommendations. Although past studies document that analysts' recommendations help price discovery process of financial securities, the recent empirical evidence on the value of analysts' recommendation is mixed. For example, Jegadeesh, Kim, Krische, and Lee (2004) find that directly following analysts' recommendations can be costly as these recommendations are often biased towards "glamour" (i.e., positive momentum, high growth, high volume, and relatively expensive) stocks and are not aligned with the expected direction between these variables and future returns. Lin and McNichols (1998) and Barber, Lehavy, and Trueman (2007) attribute this less than optimal recommendations to the conflict of interest financial analysts face in their profession. Subsequently, some studies sought after alternative, and hopefully, less-biased, public sources of information to support investment decision making. For example, Drake, Rees, and Swanson (2011) compare the investment value from analysts' recommendations 
with that from short interest. These researchers find that short interest is significantly associated in the expected direction with all 11 predictive variables they examine whereas analysts' recommendations often violate the expected direction for several variables. Furthermore, a portfolio of stocks in which short sellers and analysts conflict in their opinions about future returns can earn high abnormal returns if investors follow the short sellers.

There is ample empirical evidence that short sellers are informed traders. Specifically, past studies document evidence that short sellers are able to identify overvalued firms (e.g., Seneca, 1967; Figlewski, 1981; Senchack and Starks, 1993; Asquith and Muelbrook, 1996; Desai, Ramesh, Thiagarajan, and Balachandran, 2002) and contribute to price discovery in the financial markets (e.g., Bris, Goetzmann, and Zhu, 2007; Boehmer, Jones, and Zhang, 2008; Boehmer and Wu, 2013; Saffi and Sigurdsson, 2011). Diether, Lee, and Werner (2009) find that short sellers appear to take advantage of short-term overreaction in stock prices. Other studies examine short sellers' ability in timing specific corporate events, e.g., quarterly earnings announcement. Christophe, Ferri, and Angel (2004) examine short selling prior to earnings announcements of Nasdaq-listed firms and show that the pre-announcement short selling mostly appears to reflect firmspecific information rather than fundamental financial characteristics of firms.

Given substantial past evidence that $S I$ contains valuable information with respect to future returns, the increased availability of $S I$ data creates a good opportunity for investors to analyze the short interest data to obtain valuable price-related information and invest in a more informed manner. However, the process of obtaining SI data, analyzing 
them, understanding the right investment signals, etc., to be able to invest in a more profitable manner is a very involved and time-consuming one. Moreover, although there are a lot of studies that suggest trading strategies based on short selling data, these studies do not provide concise, simplified, and objective investment recommendations for investors to follow easily, such as following the analysts' "Buy", "Sell", and other similar recommendations. In this paper, we attempt to provide a methodology to analyze SI data and come up with investment recommendations such as analysts' recommendations.

Investors pay attention to analyst recommendations prior to making their investment decisions. However, these recommendations are often biased and yield less than optimal results. The major contribution of this paper is to provide a less biased opinion on future price movement based on short sellers' trades. We expect our study to initiate similar research in the future to enrich our understanding of short interest data.

\subsection{Data}

For our analysis, we use monthly/bi-monthly SI data from Compustat and market data including price, returns, trading volume, etc., from the Center for Research in Security Prices (CRSP). We also obtain the earnings announcement dates from Compustat. For our sample creation, we go as far back as possible. However, SI data in Compustat are available only since 1973, and therefore, our initial sample spans from 1973 to 2015 . We limit our analysis to domestic common stock (CRSP share codes 10 and 11) listed on NYSE, Amex, and Nasdaq resulting in a sample of 235,417 monthly or bimonthly observations. Table 3.1 shows the distribution of quarterly earning announcements into months. We count the number of announcements in each month of each year and then compute the time series 
average. The results show that the announcements happen each month; however, most of the announcements happen in February, May, August, and November.

We evaluate the robustness of our analysis after excluding financial services firms (SIC codes 6000-6999), regulated utility firms (SIC codes 4900-4999), and the financial crisis period spanning from 2008 to 2009.

\subsection{Methodology}

Our methodology involves examining the short position of a firm at a point of time closest to its day of quarterly earnings announcements. Prior to September 2007, SI data are available only once in a month; as of settlement on the 15th of each month, or the preceding business day if the 15th is not a business day. However, from September 2007, SI data are available also as of settlement on the last business day of the month. Furthermore, it takes a10-14 additional business days form the reporting settlement date to publish the SI data. Therefore, in our methodology, we identify the set of firms which have quarterly earnings announcement within the next 15 calendar days after SI data are published, SI publication date, to conduct our analysis and provide investment recommendations based on the short selling data available immediately before an earnings announcement. We form quintile portfolios based on SI on the SI publication date and make "Sell" recommendations for the firms in the quintile with the highest SI.

We evaluate the effectiveness of our methodology by examining the raw returns, excess returns, and abnormal returns (Boehmer, Huszar, and Jordan, 2010) of equalweighted "Sell" portfolios. Past studies examine returns over various holding periods in evaluating the information content in SI in predicting future returns: two-day (Anderson, Reeb, and Zhao, 2012), three-day (Berkman, Dimitrov, Jain, Koch, and Tice, 2009), and 
one-month (Boehmer, Huszar, and Jordan, 2010). In our study, we evaluate the postannouncement returns for a long range of holding periods, namely from one-day holding period to 30-day holding period, from the day immediately after the earnings announcement.

We compute the raw and excess returns of the equal-weighted portfolio consisting of the firms having "Sell" recommendations ahead of earnings announcements from our methodology on each SI publication date (once every month for months prior to September 2007 and twice every month since September 2007). Then we aggregate the time series of the equal-weighted returns and compute the time series average. In case of abnormal returns, we perform Fama-MacBeth cross-sectional regressions of the following fourfactor model of Fama and French (1993) and Carhart (1997):

$$
R_{p t}-R F_{t}=\alpha_{p}+\beta_{p 1} R M R F_{t}+\beta_{p 2} S M B_{t}+\beta_{p 3} H M L_{t}+\beta_{p 4} M O M_{t}+\epsilon_{p t}
$$

where $\alpha_{p}$ captures the abnormal returns, $R M R F_{t}$ is the realized market risk premium; $S M B_{t}$ is the excess return of a portfolio of small stocks over a portfolio of big stocks; $H M L_{t}$ is the excess return of a portfolio of high book-to-market-value stocks over a portfolio of low book-to-market-value stocks; and $M O M_{t}$ is the excess return on the prior-period winners portfolio over the prior-period losers portfolio. We estimate a separate cross-sectional regression for each calendar year and calculate time series average of the abnormal returns. 3.5 Results

Table 3.2 shows the raw, excess, and abnormal returns for one-day to 30-day holding period returns of the equal-weighted "Sell" portfolios. The results show that all returns are highly significant up to the 22-day holding period, whereas abnormal returns 
are significant up to the 30-day holding period. Furthermore, we see larger negative raw, excess, and abnormal returns as the holding period increases up to the 14-day holding period. More specifically, the one-day and 14-day holding period raw returns are $-0.24 \%$ and $-0.45 \%$, excess returns are $-0.25 \%$ and $-0.54 \%$, and abnormal returns are $-0.14 \%$ and $0.48 \%$, respectively. This pattern is more persistent in case of abnormal returns where returns generally continue to decrease (become larger negative) up to the 30-day holding period reaching to $-0.67 \%$. These returns are economically highly significant considering the "Sell" portfolios are formed every SI publication date which occurs at a frequency of two every month since September 2007. Therefore, if we focus on the 14-day holding period, the holding period up to which all returns seem to decrease (that is, the returns become larger negative) as the holding period increases, the annualized simple raw returns and abnormal returns are $-10.78 \%$ and $-11.4 \%$. We compute the returns by multiplying the 14-day holding period returns by 24 , as there are 24 SI publication dates in a year which means "Sell" portfolios can also be formed 24 times in a year.

To further evaluate the merit of the "Sell" recommendations based on SI, we perform subsample analysis. Fig. 1 plots the time series of the annual mean $S I$ which reveals an increasing trend during the sample period. For example, $S I$ has increased from 0.29\% in 1973 to $4.64 \%$ in 2015. However, SI increased dramatically from 2000 to 2007 when it reached $6.31 \%$ before dropping dramatically again. Therefore, for our subsample analysis, we divide the entire sample into three subsamples; the first subsample spans from 1973 to 1999 , the second subsample spans from 2000 to 2007, and the third subsample spans from 2008 to 2015. Furthermore, we exclude financial services firms (SIC codes 6000 to 6999) and utility firms (SIC codes 4900 to 4999). 
Table 3.3, 3.4, and 3.5 show the raw, excess, and abnormal returns for one-day to 30-day holding periods of the equal-weighted "Sell" portfolios for the subsamples of 1973 to 1999,2000 to 2007 , and 2008 to 2015 , respectively. In case of the first subsample, from 1973 to 1999 , the results are not thoroughly consistent. For example, although both raw and excess returns are significant for the one-day to the three-day holding period, these results are positive contrary to our expectation of negative returns. Moreover, abnormal returns are not significant for any of these holding periods. Furthermore, both raw and abnormal returns are significant for the five-day to the 11-day holding period. However, raw returns are positive, whereas abnormal returns are negative. Except for the 9-day holding period, excess returns are not significant for these holding periods.

In case of the second subsample, from 2000 to 2007, we see the similar inconsistency in results. For example, Table 3.4 shows that although both raw and excess returns are significant for each of the holding periods from the one-day to the 21-day holding period, abnormal returns are significant only for one-day, five-day, seven-day, and sixteen-day holding periods.

However, turning to the final subsample which covers the most recent time of our sample, from 2008 to 2015, we see very supportive results for the "Sell" recommendations. For example, Table 3.5, which reports the results of this subsample, shows that except for the eight-day holding period, raw, excess, and abnormal returns are highly significant for each of the holding periods from one-day to 12-day holding periods. Therefore, these results suggest that our methodology works best for the most recent time in the sample.

The results from the final subsample, from 2008 to 2015, provides good support for the methodology in the paper. However, this subsample also includes the financial crisis 
period which raises concerns about the applicability of our methodology during a normal period. Therefore, we need to evaluate if the results from the final subsample are driven by the financial crisis period. To verify the validity of this concern, we exclude 2008 to 2009 from the final subsample and perform our analysis, the results of which are presented in Table 3.6. The results show that all returns, raw, excess, and abnormal, are significant for each of the holding periods from the one-day to the 15-day holding period. Therefore, exclusion of the financial crisis period, in fact, strengthens the results and provides strong support for our methodology.

\subsection{Conclusion}

In this paper, we draw on the well documented evidence of informed short selling around quarterly earnings announcement, design a methodology that examines the preannouncement short selling, and provide specific "Sell" recommendations for firms ahead of their earnings announcements. In our methodology, we examine the short position of a firm at a point of time closest to its day of quarterly earnings announcements. More specifically, each month we identify the set of firms having the highest SI prior to their quarterly earnings announcement and make a "Sell" recommendations for these firms. We evaluate the merit of our methodology by examining the post-announcement raw, excess, and abnormal returns of the equal-weighted portfolios consisting of firms having the "Sell" recommendations. We form portfolios for one-day to 30-day holding periods. The initial results show that all returns are highly significant up to the 22-day holding period, whereas abnormal returns are significant up to the 30-day holding period. We evaluate the robustness of our results through subsample analysis which shows that the results are very 
significant and consistent for the most recent time in our sample, specifically, from 2010 to 2015 , which points to the relevance of our methodology.

Investors and other market participants heavily rely on the investment recommendations of financial analysts. However, recent studies suggest that sell-side financial analysts' recommendations can be biased because of conflict of interest, etc. Our study focuses on short sellers who are considered informed investors and who do not suffer from a conflict of interests such as financial analysts' and thus provide an alternative source of information. Investors can take into consideration the "Sell" recommendations of our methodology along with the traditional investment recommendations of financial analysts. Therefore, our study makes a significant contribution in helping investors make informed investment decisions. 
Figure 3.1 Time-series of mean short interest

This Figure shows the time-series of mean short interest $(S I)$. We compute monthly crosssectional mean $S I$ which is then used to compute annual mean $S I$. The sample period is from the fiscal year 1973 to 2015.

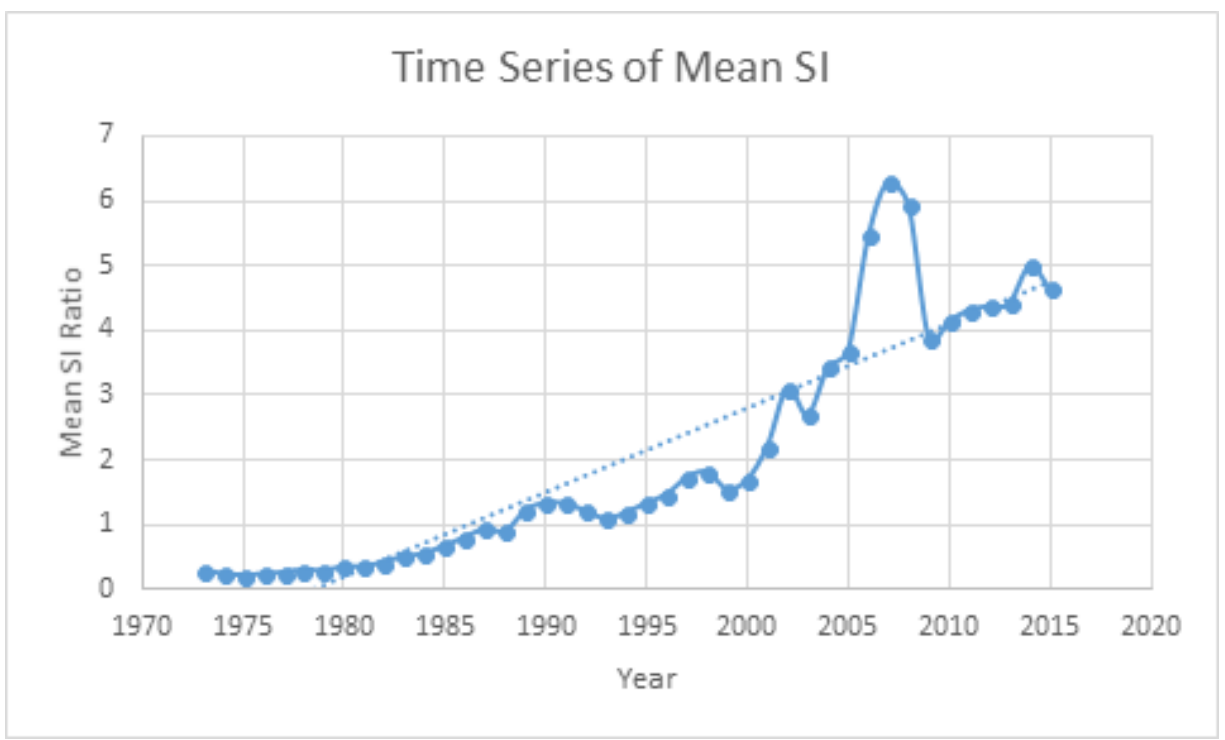




\section{Table 3.1 Monthly Distribution of Quarterly Earnings Announcement}

Table 1 shows the distribution of quarterly earnings announcements into calendar months. The number of announcements is computed in each month of each year and the time series average is reported. The sample period is from the fiscal year 1973 to 2015 .

\begin{tabular}{ccc}
\hline Month & No. of Announcements & \% Announcements \\
\hline January & 290 & 5.41 \\
February & 661 & 12.35 \\
March & 400 & 7.48 \\
April & 475 & 8.88 \\
May & 769 & 14.36 \\
June & 103 & 1.92 \\
July & 498 & 9.31 \\
August & 713 & 13.33 \\
September & 102 & 1.91 \\
October & 513 & 9.59 \\
November & 705 & 13.17 \\
December & 121 & 2.26 \\
\hline All & 5,350 & 100 \\
\hline
\end{tabular}


Table 3.2 Returns of "Sell” Portfolios (1973 to 2015)

This table shows the raw, excess, and abnormal returns of equal-weighted portfolios consisting of firms with "Sell" recommendations. Abnormal returns are the intercept from the four-factor model of Fama and French (1993) and Carhart (1997) estimated following Fama and MacBeth (1973):

$$
\begin{aligned}
R_{p t}-R F_{t}= & \alpha_{p}+\beta_{p 1} R M R F_{t}+\beta_{p 2} S M B_{t}+\beta_{p 3} H M L_{t}+\beta_{p 4} M O M_{t} \\
& +\epsilon_{p t}
\end{aligned}
$$

where $R M R F_{t}$ is market risk premium; $S M B_{t}$ is excess return of a portfolio of small stocks over a portfolio of big stocks; $H M L_{t}$ is the excess return of a portfolio of high book-tomarket-value stocks over a portfolio of low book-to-market-value stocks; and $M O M_{t}$ is the excess return on the prior-period winners portfolio over the prior-period losers portfolio. The data for the factor portfolio returns are from Wharton Research Data Services (WRDS). The sample period is from the fiscal year 1973 to 2015. Two-sided statistical significance at $1 \%, 5 \%$, and $10 \%$ is indicated as $* * *, * *$, and $*$, respectively. The significance level for the mean is based on $t$-statistics calculated with Newey-West autocorrelation-adjusted (3-lags) standard errors.

\begin{tabular}{ccccccc}
\hline \multirow{2}{*}{ Days } & \multicolumn{2}{l}{ Raw Returns } & \multicolumn{2}{c}{ Excess Returns } & \multicolumn{2}{c}{ Abnormal Returns } \\
\cline { 2 - 7 } & Returns & t-stat & Returns & t-stat & Returns & t-stat \\
\hline 1 & -0.238 & $-24.12 * * *$ & -0.247 & $-25.08 * * *$ & -0.138 & $-2.26 * *$ \\
2 & -0.228 & $-17.1 * * *$ & -0.243 & $-18.29 * * *$ & -0.130 & $-1.82 *$ \\
3 & -0.225 & $-15.57 * * *$ & -0.243 & $-16.83 * * *$ & -0.208 & $-3.14 * * *$ \\
4 & -0.284 & $-17.21 * * *$ & -0.306 & $-18.6 * * *$ & -0.292 & $-4.71 * * *$ \\
5 & -0.312 & $-17.08 * * *$ & -0.340 & $-18.65 * * *$ & -0.329 & $-4.38 * * *$ \\
6 & -0.326 & $-15.06 * * *$ & -0.362 & $-16.75 * * *$ & -0.326 & $-3.78 * * *$ \\
7 & -0.316 & $-12.46 * * *$ & -0.361 & $-14.25 * * *$ & -0.359 & $-4.17 * * *$ \\
8 & -0.317 & $-10.97 * * *$ & -0.370 & $-12.81 * * *$ & -0.385 & $-4.68 * * *$ \\
9 & -0.328 & $-10.35 * * *$ & -0.387 & $-12.2 * * *$ & -0.390 & $-4.56 * * *$ \\
10 & -0.374 & $-10.98 * * *$ & -0.437 & $-12.83 * * *$ & -0.425 & $-4.84 * * *$ \\
11 & -0.386 & $-10.86 * * *$ & -0.453 & $-12.78 * * *$ & -0.452 & $-5.01 * * *$ \\
12 & -0.376 & $-10.08 * * *$ & -0.449 & $-12.05 * * *$ & -0.443 & $-4.42 * * *$ \\
13 & -0.403 & $-10.11 * * *$ & -0.484 & $-12.14 * * *$ & -0.463 & $-4.98 * * *$ \\
14 & -0.449 & $-10.68 * * *$ & -0.538 & $-12.82 * * *$ & -0.475 & $-5.35 * * *$ \\
15 & -0.415 & $-9.32 * * *$ & -0.513 & $-11.52 * * *$ & -0.483 & $-4.89 * * *$ \\
16 & -0.355 & $-7.66 * * *$ & -0.458 & $-9.88 * * *$ & -0.504 & $-4.89 * * *$ \\
17 & -0.310 & $-6.55 * * *$ & -0.417 & $-8.8 * * *$ & -0.531 & $-4.95 * * *$ \\
18 & -0.310 & $-6.48 * * *$ & -0.421 & $-8.82 * * *$ & -0.545 & $-5.17 * * *$ \\
19 & -0.299 & $-6.22 * * *$ & -0.416 & $-8.66 * * *$ & -0.561 & $-5.58 * * *$ \\
20 & -0.281 & $-5.72 * * *$ & -0.406 & $-8.25 * * *$ & -0.560 & $-5.56 * * *$ \\
21 & -0.247 & $-4.82 * * *$ & -0.380 & $-7.42 * * *$ & -0.591 & $-5.85 * * *$ \\
22 & -0.176 & $-3.32 * * *$ & -0.317 & $-5.98 * * *$ & -0.602 & $-5.51 * * *$ \\
23 & -0.095 & $-1.75 *$ & -0.241 & $-4.45 * * *$ & -0.612 & $-5.25 * * *$ \\
& & & & & &
\end{tabular}




\begin{tabular}{lllllll}
24 & -0.073 & -1.31 & -0.223 & $-4.03 * * *$ & -0.549 & $-4.94 * * *$ \\
25 & -0.090 & -1.61 & -0.245 & $-4.38 * * *$ & -0.526 & $-4.54 * * *$ \\
26 & -0.097 & $-1.72 *$ & -0.257 & $-4.57 * * *$ & -0.534 & $-4.26 * * *$ \\
27 & -0.073 & -1.29 & -0.241 & $-4.26 * * *$ & -0.543 & $-4.25 * * *$ \\
28 & -0.042 & -0.72 & -0.219 & $-3.76 * * *$ & -0.637 & $-5.27 * * *$ \\
29 & 0.059 & 0.99 & -0.126 & $-2.11 * *$ & -0.673 & $-4.92 * * *$ \\
30 & 0.116 & $1.92 *$ & -0.074 & -1.22 & -0.667 & $-5.43 * * *$ \\
\hline
\end{tabular}


Table 3.3 Returns of "Sell” Portfolios (1973 to 1999)

This table shows the raw, excess, and abnormal returns of equal-weighted portfolios consisting of firms with "Sell" recommendations. Abnormal returns are the intercept from the four-factor model of Fama and French (1993) and Carhart (1997) estimated following Fama and MacBeth (1973):

$$
R_{p t}-R F_{t}=\alpha_{p}+\beta_{p 1} R M R F_{t}+\beta_{p 2} S M B_{t}+\beta_{p 3} H M L_{t}+\beta_{p 4} M O M_{t}+\epsilon_{p t}
$$

where $R M R F_{t}$ is market risk premium; $S M B_{t}$ is excess return of a portfolio of small stocks over a portfolio of big stocks; $H M L_{t}$ is the excess return of a portfolio of high book-tomarket-value stocks over a portfolio of low book-to-market-value stocks; and $\mathrm{MOM}_{t}$ is the excess return on the prior-period winners portfolio over the prior-period losers portfolio. The data for the factor portfolio returns are from Wharton Research Data Services (WRDS). The sample period is from the fiscal year 1973 to 1999. Two-sided statistical significance at $1 \%, 5 \%$, and $10 \%$ is indicated as $* * *, * *$, and $*$, respectively. The significance level for the mean is based on $t$-statistics calculated with Newey-West autocorrelation-adjusted (3-lags) standard errors.

\begin{tabular}{crrrrrr}
\hline \multirow{2}{*}{ Days } & \multicolumn{2}{c}{ Raw Returns } & \multicolumn{2}{c}{ Excess Returns } & \multicolumn{2}{c}{ Abnormal Returns } \\
\cline { 2 - 7 } & Returns & t-stat & Returns & t-stat & Returns & t-stat \\
\hline 1 & 0.150 & $7.58^{* * *}$ & 0.125 & $6.31 * * *$ & -0.006 & -0.12 \\
2 & 0.284 & $10.37 * * *$ & 0.241 & $8.8 * * *$ & 0.018 & 0.26 \\
3 & 0.274 & $9.75 * * *$ & 0.225 & $8.01 * * *$ & -0.057 & -0.96 \\
4 & 0.199 & $6.21 * * *$ & 0.136 & $4.26 * * *$ & -0.153 & $-2.21 * *$ \\
5 & 0.127 & $3.37 * * *$ & 0.049 & 1.3 & -0.203 & $-2.28 * *$ \\
6 & 0.158 & $3.6 * * *$ & 0.059 & 1.35 & -0.190 & $-1.81 *$ \\
7 & 0.158 & $3.17 * * *$ & 0.034 & 0.68 & -0.267 & $-2.5 * *$ \\
8 & 0.193 & $3.56 * * *$ & 0.049 & 0.9 & -0.335 & $-2.89 * * *$ \\
9 & 0.261 & $4.43 * * *$ & 0.102 & $1.73 *$ & -0.329 & $-2.75 * *$ \\
10 & 0.202 & $3.2 * * *$ & 0.030 & 0.47 & -0.383 & $-3.21 * * *$ \\
11 & 0.162 & $2.42 * *$ & -0.024 & -0.36 & -0.403 & $-3.2 * * *$ \\
12 & 0.109 & 1.5 & -0.092 & -1.27 & -0.393 & $-2.77 * *$ \\
13 & 0.059 & 0.76 & -0.163 & $-2.08 * *$ & -0.408 & $-3.1 * * *$ \\
14 & 0.029 & 0.35 & -0.218 & $-2.62 * * *$ & -0.440 & $-3.19 * * *$ \\
15 & 0.066 & 0.75 & -0.201 & $-2.29 * *$ & -0.471 & $-3.11 * * *$ \\
16 & 0.120 & 1.31 & -0.161 & $-1.76 *$ & -0.494 & $-3.19 * * *$ \\
17 & 0.135 & 1.43 & -0.159 & $-1.68 *$ & -0.556 & $-3.55^{*} * *$ \\
18 & 0.098 & 1 & -0.210 & $-2.14 * *$ & -0.563 & $-3.9 * * *$ \\
19 & 0.062 & 0.61 & -0.261 & $-2.57 * *$ & -0.565 & $-4.11 * * *$ \\
20 & 0.079 & 0.74 & -0.264 & $-2.47 * *$ & -0.561 & $-4.35 * * *$ \\
21 & 0.157 & 1.39 & -0.210 & $-1.86 *$ & -0.600 & $-4.53 * * *$ \\
22 & 0.241 & $2.05 * *$ & -0.146 & -1.24 & -0.597 & $-3.91 * * *$ \\
23 & 0.325 & $2.7 * * *$ & -0.076 & -0.63 & -0.629 & $-4.17 * * *$ \\
24 & 0.368 & $2.99 * * *$ & -0.046 & -0.37 & -0.591 & $-3.87 * * *$ \\
& & & & & &
\end{tabular}




\begin{tabular}{lrrrrrr}
25 & 0.373 & $2.97 * * *$ & -0.054 & -0.43 & -0.566 & $-3.54 * * *$ \\
26 & 0.397 & $3.1 * * *$ & -0.045 & -0.35 & -0.545 & $-3.08 * * *$ \\
27 & 0.381 & $2.91 * * *$ & -0.081 & -0.62 & -0.503 & $-2.69 * *$ \\
28 & 0.422 & $3.13 * * *$ & -0.065 & -0.49 & -0.563 & $-3.3 * * *$ \\
29 & 0.500 & $3.62 * * *$ & -0.007 & -0.05 & -0.590 & $-3.07 * * *$ \\
30 & 0.535 & $3.85 * * *$ & 0.013 & 0.09 & -0.596 & $-3.54 * * *$ \\
\hline
\end{tabular}


Table 3.4 Returns of "Sell” Portfolios (2000 to 2007)

This table shows the raw, excess, and abnormal returns of equal-weighted portfolios consisting of firms with "Sell" recommendations. Abnormal returns are the intercept from the four-factor model of Fama and French (1993) and Carhart (1997) estimated following Fama and MacBeth (1973):

$$
R_{p t}-R F_{t}=\alpha_{p}+\beta_{p 1} R M R F_{t}+\beta_{p 2} S M B_{t}+\beta_{p 3} H M L_{t}+\beta_{p 4} M O M_{t}+\epsilon_{p t}
$$

where $R M R F_{t}$ is market risk premium; $S M B_{t}$ is excess return of a portfolio of small stocks over a portfolio of big stocks; $H M L_{t}$ is the excess return of a portfolio of high book-tomarket-value stocks over a portfolio of low book-to-market-value stocks; and $M O M_{t}$ is the excess return on the prior-period winners portfolio over the prior-period losers portfolio. The data for the factor portfolio returns are from Wharton Research Data Services (WRDS). The sample period is from the fiscal year 2000 to 2007. Two-sided statistical significance at $1 \%, 5 \%$, and $10 \%$ is indicated as $* * *, * *$, and $*$, respectively. The significance level for the mean is based on $t$-statistics calculated with Newey-West autocorrelation-adjusted (3-lags) standard errors.

\begin{tabular}{ccccccc}
\hline \multirow{2}{*}{ Days } & \multicolumn{2}{l}{ Raw Returns } & \multicolumn{2}{c}{ Excess Returns } & \multicolumn{2}{c}{ Abnormal Returns } \\
\cline { 2 - 7 } & Returns & t-stat & Returns & t-stat & Returns & t-stat \\
\hline 1 & -0.441 & $-22.38 * * *$ & -0.455 & $-23.07 * * *$ & -0.370 & $-2.96 * *$ \\
2 & -0.537 & $-22.02 * * *$ & -0.559 & $-22.93 * * *$ & -0.221 & -1.28 \\
3 & -0.623 & $-23.28 * * *$ & -0.650 & $-24.29 * * *$ & -0.113 & -0.36 \\
4 & -0.768 & $-24.59 * * *$ & -0.802 & $-25.65 * * *$ & -0.195 & -0.61 \\
5 & -0.828 & $-24.45 * * *$ & -0.870 & $-25.66 * * *$ & -0.708 & $-5.6 * * *$ \\
6 & -0.854 & $-23.53 * * *$ & -0.908 & $-24.98 * * *$ & 2.238 & 0.86 \\
7 & -0.822 & $-19.45 * * *$ & -0.889 & $-21.01 * * *$ & -0.937 & $-3.05 * *$ \\
8 & -0.803 & $-16.49 * * *$ & -0.883 & $-18.09 * * *$ & 0.905 & 0.68 \\
9 & -0.807 & $-15.27 * * *$ & -0.895 & $-16.9 * * *$ & 0.927 & 0.66 \\
10 & -0.865 & $-15.32 * * *$ & -0.959 & $-16.95 * * *$ & 0.323 & 0.37 \\
11 & -0.906 & $-15.42 * * *$ & -1.006 & $-17.09 * * *$ & -2.235 & -1.58 \\
12 & -0.860 & $-13.82 * * *$ & -0.969 & $-15.53 * * *$ & -52.037 & -1.11 \\
13 & -0.771 & $-11.25 * * *$ & -0.891 & $-12.97 * * *$ & 1.426 & 0.7 \\
14 & -0.679 & $-9.12 * * *$ & -0.812 & $-10.87 * * *$ & 3.141 & 0.89 \\
15 & -0.578 & $-7.35 * * *$ & -0.723 & $-9.17 * * *$ & 3.530 & 0.9 \\
16 & -0.457 & $-5.6 * * *$ & -0.610 & $-7.45 * * *$ & -1.777 & $-1.91 *$ \\
17 & -0.409 & $-4.94 * * *$ & -0.568 & $-6.84 * * *$ & 12.843 & 1.04 \\
18 & -0.426 & $-4.99 * * *$ & -0.591 & $-6.9 * * *$ & 0.616 & 0.47 \\
19 & -0.408 & $-4.65 * * *$ & -0.582 & $-6.59 * * *$ & 0.658 & 0.48 \\
20 & -0.372 & $-4.03 * * *$ & -0.556 & $-6 * * *$ & 1.511 & 0.69 \\
21 & -0.292 & $-3.11 * * *$ & -0.490 & $-5.18 * * *$ & -7.659 & -1.25 \\
22 & -0.052 & -0.54 & -0.261 & $-2.73 * * *$ & -8.100 & -1.24 \\
23 & 0.149 & 1.57 & -0.068 & -0.71 & -4.329 & -1.39 \\
24 & 0.256 & $2.66 * * *$ & 0.034 & 0.35 & -49.075 & -1.12 \\
& & & & & &
\end{tabular}




\begin{tabular}{rrrrrrr}
25 & 0.269 & $2.74 * * *$ & 0.040 & 0.41 & - & -1.11 \\
26 & 0.248 & $2.47 * *$ & 0.011 & 0.11 & 2.573 & 0.83 \\
27 & 0.309 & $3 * * *$ & 0.061 & 0.59 & 3.167 & 0.85 \\
28 & 0.318 & $2.98 * * *$ & 0.057 & 0.53 & 9.910 & 0.99 \\
29 & 0.407 & $3.72 * * *$ & 0.134 & 1.21 & -1.924 & $-2.82 * *$ \\
30 & 0.463 & $4.17 * * *$ & 0.181 & 1.62 & 3.660 & 0.83 \\
\hline
\end{tabular}


Table 3.5 Returns of "Sell” Portfolios (2008 to 2015)

This table shows the raw, excess, and abnormal returns of equal-weighted portfolios consisting of firms with "Sell" recommendations. Abnormal returns are the intercept from the four-factor model of Fama and French (1993) and Carhart (1997) estimated following Fama and MacBeth (1973):

$$
R_{p t}-R F_{t}=\alpha_{p}+\beta_{p 1} R M R F_{t}+\beta_{p 2} S M B_{t}+\beta_{p 3} H M L_{t}+\beta_{p 4} M O M_{t}+\epsilon_{p t}
$$

where $R M R F_{t}$ is market risk premium; $S M B_{t}$ is excess return of a portfolio of small stocks over a portfolio of big stocks; $H M L_{t}$ is the excess return of a portfolio of high book-tomarket-value stocks over a portfolio of low book-to-market-value stocks; and $M O M_{t}$ is the excess return on the prior-period winners portfolio over the prior-period losers portfolio. The data for the factor portfolio returns are from Wharton Research Data Services (WRDS). The sample period is from the fiscal year 2008 to 2015. Two-sided statistical significance at $1 \%, 5 \%$, and $10 \%$ is indicated as $* * *, * *$, and $*$, respectively. The significance level for the mean is based on $t$-statistics calculated with Newey-West autocorrelation-adjusted (3-lags) standard errors.

\begin{tabular}{crrrrrr}
\hline \multirow{2}{*}{ Days } & \multicolumn{2}{l}{ Raw Returns } & \multicolumn{2}{c}{ Excess Returns } & \multicolumn{2}{c}{ Abnormal Returns } \\
\cline { 2 - 7 } & Returns & t-stat & Returns & t-stat & Returns & t-stat \\
\hline 1 & -0.352 & $-19.94 * * *$ & -0.353 & $-20 * * *$ & -0.464 & $-6.56 * * *$ \\
2 & -0.346 & $-14.86 * * *$ & -0.348 & $-14.93 * * *$ & -0.336 & $-3.86 * * *$ \\
3 & -0.288 & $-11.36 * * *$ & -0.290 & $-11.44 * * *$ & -0.317 & $-3.02 * *$ \\
4 & -0.277 & $-9.79 * * *$ & -0.280 & $-9.88 * * *$ & -0.298 & $-2.15 *$ \\
5 & -0.286 & $-9.16 * * *$ & -0.290 & $-9.26 * * *$ & -0.460 & $-7.31 * * *$ \\
6 & -0.330 & $-8.73 * * *$ & -0.334 & $-8.84 * * *$ & -0.714 & $-3.02 * *$ \\
7 & -0.323 & $-7.22 * * *$ & -0.328 & $-7.34 * * *$ & -0.536 & $-4.46 * * *$ \\
8 & -0.340 & $-6.65 * * *$ & -0.347 & $-6.77 * * *$ & -0.251 & -1.37 \\
9 & -0.378 & $-6.72 * * *$ & -0.385 & $-6.84 * * *$ & -0.493 & $-3.67 * * *$ \\
10 & -0.413 & $-6.82 * * *$ & -0.420 & $-6.94 * * *$ & -0.361 & $-3.11 * *$ \\
11 & -0.398 & $-6.4 * * *$ & -0.406 & $-6.52 * * *$ & -0.483 & $-3.94 * * *$ \\
12 & -0.362 & $-5.58 * * *$ & -0.370 & $-5.7 * * *$ & -0.475 & $-3.55 * * *$ \\
13 & -0.450 & $-6.5 * * *$ & -0.459 & $-6.63 * * *$ & -0.153 & -0.72 \\
14 & -0.565 & $-7.79 * * *$ & -0.575 & $-7.93 * * *$ & -0.107 & -0.44 \\
15 & -0.568 & $-7.47 * * *$ & -0.579 & $-7.61 * * *$ & -0.718 & -1.82 \\
16 & -0.518 & $-6.57 * * *$ & -0.530 & $-6.72 * * *$ & 0.169 & 0.43 \\
17 & -0.465 & $-5.75 * * *$ & -0.477 & $-5.9 * * *$ & -0.134 & -1.35 \\
18 & -0.441 & $-5.49 * * *$ & -0.453 & $-5.64 * * *$ & 0.111 & 0.37 \\
19 & -0.392 & $-4.92 * * *$ & -0.405 & $-5.09 * * *$ & -0.110 & -1.03 \\
20 & -0.365 & $-4.54 * * *$ & -0.379 & $-4.71 * * *$ & -0.119 & -1.03 \\
21 & -0.328 & $-3.9 * * *$ & -0.343 & $-4.07 * * *$ & -0.614 & -1.68 \\
22 & -0.304 & $-3.48 * * *$ & -0.320 & $-3.66 * * *$ & -0.592 & -1.75 \\
23 & -0.251 & $-2.81 * * *$ & -0.267 & $-2.99 * * *$ & -0.705 & -1.54 \\
24 & -0.275 & $-3 * * *$ & -0.292 & $-3.19 * * *$ & -0.189 & -1.62 \\
& & & & & & \\
& & & & & &
\end{tabular}




\begin{tabular}{lllllrl}
25 & -0.333 & $-3.63 * * *$ & -0.351 & $-3.82 * * *$ & 0.257 & 0.57 \\
26 & -0.308 & $-3.38^{* * *}$ & -0.326 & $-3.58 * * *$ & 0.368 & 0.6 \\
27 & -0.240 & $-2.66^{* * *}$ & -0.259 & $-2.86^{* * *}$ & -0.435 & $-2.85^{* *}$ \\
28 & -0.178 & $-1.91 *$ & -0.198 & $-2.12^{* *}$ & -1.259 & -1.74 \\
29 & -0.055 & -0.57 & -0.075 & -0.79 & -0.997 & $-2.13 *$ \\
30 & -0.002 & -0.02 & -0.023 & -0.23 & -1.117 & $-1.94 *$ \\
\hline
\end{tabular}


Table 3.6 Returns of "Sell” Portfolios (2010 to 2015)

This table shows the raw, excess, and abnormal returns of equal-weighted portfolios consisting of firms with "Sell" recommendations. Abnormal returns are the intercept from the four-factor model of Fama and French (1993) and Carhart (1997) estimated following Fama and MacBeth (1973):

$$
R_{p t}-R F_{t}=\alpha_{p}+\beta_{p 1} R M R F_{t}+\beta_{p 2} S M B_{t}+\beta_{p 3} H M L_{t}+\beta_{p 4} M O M_{t}+\epsilon_{p t}
$$

where $R M R F_{t}$ is market risk premium; $S M B_{t}$ is excess return of a portfolio of small stocks over a portfolio of big stocks; $H M L_{t}$ is the excess return of a portfolio of high book-tomarket-value stocks over a portfolio of low book-to-market-value stocks; and $M O M_{t}$ is the excess return on the prior-period winners portfolio over the prior-period losers portfolio. The data for the factor portfolio returns are from Wharton Research Data Services (WRDS). The sample period is from the fiscal year 2010 to 2015. Two-sided statistical significance at $1 \%, 5 \%$, and $10 \%$ is indicated as $* * *, * *$, and $*$, respectively. The significance level for the mean is based on $t$-statistics calculated with Newey-West autocorrelation-adjusted (3-lags) standard errors.

\begin{tabular}{|c|c|c|c|c|c|c|}
\hline \multirow{2}{*}{ Days } & \multicolumn{2}{|c|}{ Raw Returns } & \multicolumn{2}{|c|}{ Excess Returns } & \multicolumn{2}{|c|}{ Abnormal Returns } \\
\hline & Returns & t-stat & Returns & t-stat & Returns & t-stat \\
\hline 1 & $\begin{array}{l}-0.449 \\
\end{array}$ & $-23.43 * * *$ & $\begin{array}{l}-0.449 \\
\end{array}$ & $-23.44 * * *$ & -0.449 & $-10.56^{* * *}$ \\
\hline 2 & -0.466 & $-18.81 * * *$ & -0.466 & $-18.82 * * *$ & -0.449 & $-6.73 * * *$ \\
\hline 3 & -0.443 & $-17.05 * * *$ & -0.443 & $-17.06 * * *$ & -0.442 & $-6.97 * * *$ \\
\hline 4 & -0.452 & $-15.91 * * *$ & -0.453 & $-15.93 * * *$ & -0.482 & $-5.28 * * *$ \\
\hline 5 & -0.485 & $-15.59 * * *$ & -0.485 & $-15.61 * * *$ & -0.521 & $-4.52 * * *$ \\
\hline 6 & -0.529 & $-14.68 * * *$ & -0.530 & $-14.7 * * *$ & -0.523 & $-3.68 * *$ \\
\hline 7 & -0.568 & $-13.39 * * *$ & -0.568 & $-13.41 * * *$ & -0.501 & $-3.24 * *$ \\
\hline 8 & -0.586 & $-11.92 * * *$ & -0.587 & $-11.94 * * *$ & -0.462 & $-2.57 * *$ \\
\hline 9 & -0.620 & $-11.45^{* * *}$ & -0.622 & $-11.47 * * *$ & -0.449 & $-2.43^{*}$ \\
\hline 10 & -0.675 & $-11.61 * * *$ & -0.676 & $-11.62 * * *$ & -0.459 & $-2.61 * *$ \\
\hline 11 & -0.619 & $-10.37 * * *$ & -0.621 & $-10.39 * * *$ & -0.456 & $-2.56^{*}$ \\
\hline 12 & -0.609 & $-10.07 * * *$ & -0.610 & $-10.1 * * *$ & -0.434 & $-2.36^{*}$ \\
\hline 13 & -0.671 & $-10.76^{* * *}$ & -0.673 & $-10.78 * * *$ & -0.418 & $-2.3 *$ \\
\hline 14 & -0.818 & $-12.32 * * *$ & -0.819 & $-12.34 * * *$ & -0.421 & $-2.97 * *$ \\
\hline 15 & -0.822 & $-11.65^{* * *}$ & -0.824 & $-11.67 * * *$ & -0.351 & $-2.25^{*}$ \\
\hline 16 & -0.786 & $-10.58 * * *$ & -0.788 & $-10.61 * * *$ & -0.307 & -1.84 \\
\hline 17 & -0.717 & $-9.37 * * *$ & -0.719 & $-9.39 * * *$ & -0.242 & -1.51 \\
\hline 18 & -0.701 & $-9.04 * * *$ & -0.704 & $-9.07 * * *$ & -0.255 & -1.66 \\
\hline 19 & -0.683 & $-8.72 * * *$ & -0.686 & $-8.75^{* * *}$ & -0.241 & -1.79 \\
\hline 20 & -0.655 & $-8.27 * * *$ & -0.657 & $-8.29 * * *$ & -0.248 & -1.59 \\
\hline 21 & -0.675 & $-8.22 * * *$ & -0.678 & $-8.25 * * *$ & -0.268 & -1.79 \\
\hline 22 & -0.668 & $-7.87 * * *$ & -0.670 & $-7.9 * * *$ & -0.252 & -1.6 \\
\hline 23 & -0.616 & $-7.15 * * *$ & -0.619 & $-7.18 * * *$ & -0.230 & -1.32 \\
\hline 24 & -0.653 & $-7.5 * * *$ & -0.656 & $-7.53 * * *$ & -0.252 & -1.47 \\
\hline
\end{tabular}




\begin{tabular}{lllllll}
25 & -0.687 & $-7.89 * * *$ & -0.690 & $-7.92 * * *$ & -0.243 & -1.64 \\
26 & -0.718 & $-8.36 * * *$ & -0.721 & $-8.39 * * *$ & -0.335 & -1.74 \\
27 & -0.695 & $-8.23 * * *$ & -0.698 & $-8.26 * * *$ & -0.382 & -1.83 \\
28 & -0.699 & $-8.13 * * *$ & -0.702 & $-8.17 * * *$ & -0.524 & $-2.51 *$ \\
29 & -0.618 & $-7.05 * * *$ & -0.622 & $-7.09 * * *$ & -0.541 & $-2.51 *$ \\
30 & -0.591 & $-6.62 * * *$ & -0.594 & $-6.65 * * *$ & -0.542 & $-2.57 * *$ \\
\hline
\end{tabular}




\section{REFERENCES}

Allen, F., S. Morris, and A. Postlewaite, 1993, Finite bubbles with short sale constraints and asymmetric information, Journal of Economic Theory 61, 206-229.

Anderson, Ronald C., David M. Reeb, and Wanli Zhao, 2012, Family-controlled firms and informed trading: evidence from short sales, Journal of Finance 67, 351-385.

Asquith, Paul, and Lisa Meulbroek, 1996, An empirical examination of short interest, Working paper, Harvard University.

Asquith, Paul, Parag A. Pathak, and Jay R. Ritter, 2005, Short interest, institutional ownership, and stock returns, Journal of Financial Economics 78, 243-276.

Baker, Malcolm, and Jeffrey Wurgler, 2002, Market timing and capital structure, Journal of Finance 57, 1-32.

Barber, Brad M., Reuven Lehavy, and Brett Trueman, 2007, Comparing the stock recommendation performance of investment banks and independent research firms, Journal of Financial Economics 85, 490-517.

Boehmer, Ekkehart, Charles M. Jones, and Xiaoyan Zhang, 2008, Which shorts are informed? Journal of Finance 63, 491-527.

Boehmer, Ekkehart, and Juan (Julie) Wu, 2013, Short selling and the price discovery process, Review of Financial Studies 26, 287-322.

Bris, Arturo, William N. Goetzmann, and Ning Zhu, 2007, Efficiency and the bear: short sales and markets around the world, Journal of Finance 62, 1029-1079.

Byrd, John W., and Kent A. Hickman, 1992, Do outside directors monitor managers?: Evidence from tender offer bids, Journal of Financial Economics 32, 195-221.

Chen, Joseph, Harrison Hong, and Jeremy C. Stein, 2002, Breadth of ownership and stock returns, Journal of Financial Economics 66, 171-205.

Christophe, Stephen E., Michael G. Ferri, and James J. Angel, 2004, Short-Selling Prior to Earnings Announcements, Journal of Finance 59, 1845-1876.

Dechow, Patricia M., Amy P. Hutton, Lisa Meulbroek, and Richard G. Sloan, 2001, Shortsellers, fundamental analysis, and stock returns, Journal of Financial Economics 61, 77106.

Desai, Ashay, Mark Kroll, and Peter Wright, 2003, CEO duality, board monitoring, and acquisition performance: a test of competing theories, Journal of Business Strategies 20, 137-156. 
Desai, Hemang, K. Ramesh, S. R. Thiagarajan, and Bala V. Balachandran, 2002, An investigation of the informational role of short interest in the Nasdaq market, Journal of Finance 57, 2263-2287.

Diamond, Douglas W., and Robert E. Verrecchia, 1987, Constraints on short-selling and asset price adjustment to private information, Journal of Financial Economics 18, 277-311.

Diether, Karl B., Kuan-Hui Lee, and Ingrid M. Werner, 2009, Short-Sale Strategies and Return Predictability, Review of Financial Studies 22, 575-607.

Dong, Ming, David Hirshleifer, and Siew H. Teoh, 2012, Overvalued equity and financing decisions, Review of Financial Studies 25, 3645-3683.

Drake, Michael S., Lynn Rees, and Edward P. Swanson, 2011, Should Investors Follow the Prophets or the Bears? Evidence on the Use of Public Information by Analysts and Short Sellers, The Accounting Review 86, 101-130.

Duarte, Jefferson, Xiaoxia Lou, and Ronnie Sadka, 2006, Can Liquidity Events Explain the Low-Short-Interest Puzzle? Implications from the Options Market, Working paper, University of Washington.

Fama, Eugene F., and Michael C. Jensen, 1983, Separation of Ownership and Control, Journal of Law and Economics 26, 301-325.

Fang, Vivian W., Allen H. Huang, and Jonathan M. Karpoff, 2016, Short Selling and Earnings Management: A Controlled Experiment, Journal of Finance 71, 1251-1294.

Figlewski, Stephen, 1981, The informational effects of restrictions on short sales: some empirical evidence, Journal of Financial and Quantitative Analysis 16, 463-476.

Grullon, Gustavo, Sébastien Michenaud, and James P. Weston, 2015, The real effects of short-selling constraints, Review of Financial Studies 28, 1737-1767.

Harrison, J. M., and David M. Kreps, 1978, Speculative investor behavior in a stock market with heterogeneous expectations, Quarterly Journal of Economics 92, 323-336.

Henry, Tyler R., Darren J. Kisgen, and Juan (Julie) Wu, 2015, Equity short selling and bond rating downgrades, Journal of Financial Intermediation 24, 89-111.

Hirshleifer, David, Siew H. Teoh, and Jeff J. Yu, 2011, Short arbitrage, return asymmetry, and the accrual anomaly, Review of Financial Studies 24, 2429-2461.

Hong, Harrison, and Jeremy C. Stein, 2003, Differences of opinion, short-sales constraints, and market crashes, Review of Financial Studies 16, 487-525. 
Hovakimian, Armen, 2006, Are observed capital structures determined by equity market timing? Journal of Financial and Quantitative Analysis 41, 221-243.

Hovakimian, Armen, Tim Opler, and Sheridan Titman, 2001, The debt-equity choice, Journal of Financial and Quantitative Analysis 36, 1-24.

Ikenberry, David, Josef Lakonishok, and Theo Vermaelen, 1995, Market underreaction to open market share repurchases, Journal of Financial Economics 39, 181-208.

Jegadeesh, Narasimhan, Joonghyuk Kim, Susan D. Krische, and Charles M. C. Lee, 2004, Analyzing the Analysts: When Do Recommendations Add Value? Journal of Finance 59, 1083-1124.

Karpoff, Jonathan M., and Xiaoxia Lou, 2010, Short sellers and financial misconduct, Journal of Finance 65, 1879-1913.

Kayhan, Ayla, and Sheridan Titman, 2007, Firms' histories and their capital structures, Journal of Financial Economics 83, 1-32.

Lee, Charles M. C., James Myers and Bhaskaran Swaminathan, 1999, What is the Intrinsic Value of the Dow? Journal of Finance 54, 1693-1741.

Lemmon, Michael L., Michael R. Roberts, and Jaime F. Zender, 2008, Back to the Beginning: Persistence and the Cross-Section of Corporate Capital Structure, Journal of Finance 63, 1575-1608.

Lin, Hsiou-wei, and Maureen F. McNichols, 1998, Underwriting relationships, analysts' earnings forecasts and investment recommendations, Journal of Accounting and Economics 25, 101-127.

Linck, James S., Jeffry M. Netter, and Tina Yang, 2009, The Effects and Unintended Consequences of the Sarbanes-Oxley Act on the Supply and Demand for Directors, Review of Financial Studies 22, 3287-3328.

Marsh, Paul, 1982, The choice between equity and debt: an empirical study, Journal of Finance 37, 121-144.

Miller, Merton H., 1977, Debt and taxes*, Journal of Finance 32, 261-275.

Nagel, Stefan, 2005, Short sales, institutional investors and the cross-section of stock returns, Journal of Financial Economics 78, 277-309.

Nguyen, Bang D., and Kasper M. Nielsen, 2010, The value of independent directors: Evidence from sudden deaths, Journal of Financial Economics 98, 550-567.

Ohlson, James A., 1995, Earnings, Book Values, and Dividends in Equity Valuation, Contemporary Accounting Research 11, 661-687. 
Pagano, Marco, Fabio Panetta, and Luigi Zingales, 1998, Why do companies go public? An Empirical Analysis, Journal of Finance 53, 27-64.

Polk, Christopher, and Paola Sapienza, 2009, The stock market and corporate investment: a test of catering theory, Review of Financial Studies 22, 187-217.

Rajan, Raghuram G., and Luigi Zingales, 1995, What do we know about capital structure? some evidence from international data, Journal of Finance 50, 1421-1460.

Saffi, Pedro A. C., and Kari Sigurdsson, 2011, Price efficiency and short selling, Review of Financial Studies 24, 821-852.

Scheinkman, José A, and Wei Xiong, 2003, Overconfidence and speculative bubbles, Journal of Political Economy 111, 1183-1220.

Senchack, A. J., and Laura T. Starks, 1993, Short-sale restrictions and market reaction to short-interest announcements, Journal of Financial and Quantitative Analysis 28, 177-194.

Seneca, Joseph J., 1967, Short interest: bearish or bullish? Journal of Finance 22, 67-70.

Shivdasani, Anil, and David Yermack, 1999, CEO Involvement in the Selection of New Board Members: An Empirical Analysis, Journal of Finance 54, 1829-1853.

Shleifer, Andrei, and Robert W. Vishny, 1997, The Limits of Arbitrage, Journal of Finance 52, 35-55.

Titman, Sheridan, and Roberto Wessels, 1988, The determinants of capital structure choice, Journal of Finance 43, 1-19.

Weisbach, Michael S., 1988, Outside directors and CEO turnover, Journal of Financial Economics 20, 431-460.

Welch, Ivo, 2004, Capital structure and stock returns, Journal of Political Economy 112, 106-132. 


\section{APPENDIX: VARIABLE DEFINITIONS}

\begin{tabular}{|c|c|}
\hline Variable & Definitions \\
\hline Book Equity $(B E)$ & $\begin{array}{l}\text { Total assets }- \text { [total liabilities }+ \text { preferred stock }]+ \\
\text { deferred taxes }+ \text { convertible debt. }\end{array}$ \\
\hline $\begin{array}{l}\text { Market Equity }(M E) \\
\text { Book Leverage }(B L)\end{array}$ & $\begin{array}{l}\text { Common shares outstanding x price. } \\
\text { [Short-term + long-term debt]/[Total Assets] }\end{array}$ \\
\hline Market Leverage $(M L)$ & $\begin{array}{l}\text { [Short-term + long-term debt]/[Total Assets - Book } \\
\text { Equity + Market Equity] }\end{array}$ \\
\hline $\begin{array}{l}\text { Property, Plant \& Equipment } \\
(P P E)\end{array}$ & Net property, plant, and equipment/total assets. \\
\hline Profitability $(E B I T D)$ & $\begin{array}{l}\text { Earnings before interest, tax, and depreciation/total } \\
\text { assets. }\end{array}$ \\
\hline $\begin{array}{l}\text { Research and Development } \\
\text { Expenses }(R \& D)\end{array}$ & Research and development expense/sales. \\
\hline Selling Expenses $(S E)$ & Selling expense/sales. \\
\hline Firm Size (Size) & Natural logarithm of net sales. \\
\hline \multirow[t]{2}{*}{ Abnormal Short Interest $(A B S I)$} & $\begin{array}{l}\text { Pre-announcement short interest divided by non- } \\
\text { announcement short interest, all minus } 1 \text { : } \\
\qquad A B S I_{i,(t-5 \text { to } t-1)}=\frac{S I_{i,(t-5 \text { to } t-1)}}{S I_{i,(t-62 \text { to } t-6)}}-1\end{array}$ \\
\hline & $\begin{array}{l}\text { where } t \text { indicates the date of earnings announcement } \\
\text { for the firm } i \text {. }\end{array}$ \\
\hline Market-to-book $(M B)$ & $\begin{array}{l}\text { The product of shares outstanding and price divided } \\
\text { by the book value of total common equity, all at the } \\
\text { end of each quarter. }\end{array}$ \\
\hline Dispersion & $\begin{array}{l}\text { The standard deviation of analysts' forecasts divided } \\
\text { by the previous quarter-end stock price. }\end{array}$ \\
\hline Performance & $\begin{array}{l}\text { Prior quarter-end income before extraordinary items } \\
\text { divided by prior quarter-end total assets. }\end{array}$ \\
\hline Liquidity & $\begin{array}{l}\text { The natural log of daily trading volume averaged } \\
\text { across each quarter. }\end{array}$ \\
\hline Spread & $\begin{array}{l}\text { The daily bid price less daily ask price, divided by the } \\
\text { average of the bid price plus the ask price, averaged } \\
\text { across each quarter. }\end{array}$ \\
\hline Vol & $\begin{array}{l}\text { The standard deviation of daily stock returns for each } \\
\text { quarter. }\end{array}$ \\
\hline AmexDummy & $\begin{array}{l}\text { A dummy variable coded one for a firm listed on the } \\
\text { American Stock Exchange, and zero otherwise. }\end{array}$ \\
\hline NasdaqDummy & $\begin{array}{l}\text { A dummy variable coded one for a firm listed on the } \\
\text { Nasdaq Stock Market (SM), and zero otherwise. }\end{array}$ \\
\hline $\begin{array}{l}\text { Unexpected quarterly earnings } \\
(U Q E)\end{array}$ & $\begin{array}{l}\text { It is defined as the residual from the following } \\
\text { regression: }\end{array}$ \\
\hline
\end{tabular}




$$
\begin{gathered}
E P S_{i, q}=\alpha+\beta_{1} E P S_{i, q-1}+\beta_{2} E P S_{i, q-4} \\
+\beta_{3} E P S_{i, q-8}+\varepsilon_{i, q}
\end{gathered}
$$

where $i$ indexes firms; EPS is actual earnings per share of the announcement quarter $(q)$, the prior quarter $(q-1)$, one year ago $(q-4)$, and two years ago $(q-8)$.

Prediction

IndependentBoards
A dummy variable coded one when $A B S I$ is positive and $U Q E$ is negative, and zero otherwise.

It is dummy variable coded one if independent directors constitute a majority of the board and zero otherwise. 
VITA

MOHAMMAD ANISUR RAHMAN

Born, Brahmanbaria, Bangladesh

2004

B.B.A.

University of Khulna

Khulna, Bangladesh

2014

M.B.A., Finance

Willamette University

Salem, Oregon

2014-2018

Graduate Teaching Assistant

Florida International University

Miami, Florida

\section{PUBLICATIONS AND PRESENTATIONS}

Short Sellers' Heterogeneity and Predictive Signals, with Bakhtear Talukdar and A. M. Parhizgari. 2017 Global Finance Conference, Hempstead, NY; 2017 Southern Finance Association Annual Meetings, Key West, FL; 2018 Eastern Finance Association Annual Meeting, Philadelphia, PA;

"Short sellers and managerial equity market timing during high firm valuation" with Suchismita Mishra and Özde Öztekin. 2017 FMA Doctoral Student Consortium, Boston, Massachusetts. 